\title{
Irreversible Electroporation: Background, Theory, and Review of Recent Developments in Clinical Oncology
}

\author{
Kenneth N. Aycock, BS, and Rafael V. Davalos, PhD
}

\begin{abstract}
Irreversible electroporation (IRE) has established a clinical niche as an alternative to thermal ablation for the eradication of unresectable tumors, particularly those near critical vascular structures. IRE has been used in over 50 independent clinical trials and has shown clinical success when used as a standalone treatment and as a single component within combinatorial treatment paradigms. Recently, many studies evaluating IRE in larger patient cohorts and alongside other novel therapies have been reported. Here, we present the basic principles of reversible electroporation and IRE followed by a review of preclinical and clinical data with a focus on tumors in three organ systems in which IRE has shown great promise: the prostate, pancreas, and liver. Finally, we discuss alternative and future developments, which will likely further advance the use of IRE in the clinic.
\end{abstract}

Keywords: irreversible electroporation, pulsed electric field, electroporation, interventional oncology

\section{Introduction}

$\mathbf{E}$ LECTROPORATION IS A BIOPHYSICAL phenomenon in which cellular membranes exhibit increased permeability to ions and macromolecules when exposed to external electric fields. Although the exact mechanisms of electroporation have not been fully elucidated, the scientific community has mostly come to agreement that permeabilizing nanoscale defects or "nanopores" are formed in cellular membranes upon exposure to high-amplitude electric fields of sufficient duration. ${ }^{1}$ This phenomenon is manifested in two distinct forms: reversible electroporation, in which permeabilizing structures are transient and membrane integrity is quickly recovered; and irreversible electroporation (IRE), in which permeabilization disrupts cellular homeostasis and leads to cell death.

\section{The discovery of reversible electroporation}

The earliest reports of electroporation date back over two centuries, but the most widely recognized initial discoveries originate in the 1950s when Stampfli and Willi studied the "electrical breakdown" of nodes of Ranvier extracted from frogs. ${ }^{2,3}$ A decade later, intense electric fields were used to nonthermally kill microorganisms and to induce changes in permeability of vesicular membranes, leading to the release of catecholamines. ${ }^{4,5}$ A series of investigations by Kinosita and Tsong in the 1970s showed that high-amplitude pulsed electric fields (PEFs) could be tuned to generate pores of different sizes in erythrocyte membranes, allowing for se- lective internalization of normally impermeant molecules. ${ }^{6,7}$ They also demonstrated the increase in conductivity that follows the application of high voltage pulses and the ability to directly cause hemolysis with induced electric fields. ${ }^{8,9}$ These early contributions provided evidence supporting the theory of aqueous pore formation, which was first published in $1979 .{ }^{10}$ We acknowledge the perpetuity of this work as the fundamental principles introduced still underlie our current understanding of electroporation.

Within the next decade, seminal investigations established the ability of PEFs to increase uptake of genes and chemotherapeutics, leading to the development of the prominent fields now known as electrochemotherapy (ECT) and electrogene transfer (EGT). ${ }^{1-13}$ As its name implies, ECT utilizes reversible electroporation to locally increase cellular uptake of chemotherapeutics, namely bleomycin or cisplatin, which allows for lower drug concentrations and can limit offtarget toxicity. EGT employs similar techniques to introduce plasmid DNA into cells. This technique is now widely used for laboratory transfection assays, but its clinical utility is still being developed.

The aforementioned studies, along with many others, laid the framework for clinical applications of electroporation, which focused on enhancing transmembrane transport of existing biological and pharmaceutical agents until the $21 \mathrm{st}$ century. During these two decades, electroporation was not used directly to injure cells, and IRE was largely viewed as an undesirable side effect of overtreatment.

\footnotetext{
Department of Biomedical Engineering and Mechanics, Virginia Tech-Wake Forest University, Blacksburg, Virginia.
}

(c) Kenneth N. Aycock and Rafael V. Davalos 2019; Published by Mary Ann Liebert, Inc. This Open Access article is distributed under the terms of the Creative Commons License (http://creativecommons.org/licenses/by/4.0), which permits unrestricted use, distribution, and reproduction in any medium, provided the original work is properly cited. 


\section{IRE as a tissue ablation modality}

In 2005, however, Davalos et al. proposed IRE as a standalone soft tissue ablation technique. ${ }^{14}$ Their original work showed numerically that electric fields capable of nonthermal IRE exist and could destroy clinically relevant volumes of tissue. Unlike existing focal ablation techniques that indiscriminately eliminate all biomolecules within a certain proximity, IRE allows for preservation of collagenous and other protein and/or lipid-based structures including vasculature ${ }^{15}$ and ductal networks. ${ }^{16}$ It has also been shown that carefully planned IRE treatments cause minimal long-term damage to myelinated neurons, but that overtreatment or direct physical penetration can injure these structures. ${ }^{17}$ The inherent advantages of IRE compared with other focal cancer therapies, such as reduced treatment time, reduced vascular complications, decreased risk of overtreatment, and minimized heat-sink effect when administered near vessels, led to an array of early publications evaluating the efficacy and feasibility of IRE to nonthermally ablate healthy and malignant soft tissues including the liver, ${ }^{18-20}$ prostate, $^{21,22}$ pancreas, ${ }^{23}$ kidney, ${ }^{24}$ lung, ${ }^{25,26}$ and brain. ${ }^{27-30}$ Hundreds of follow-up studies have scrutinized the application of IRE in these tissues and others. Importantly, a large number of preclinical and clinical reports have been published in recent years. This review will serve to present these results in an organized manner to serve as a comprehensive reference for the interested reader. To maintain brevity, our discussion will focus on treatments in the prostate, pancreas, and liver, as tumors in these tissues present obvious difficulties that IRE has the potential to address.

\section{Mechanisms of Electroporation and IRE}

\section{A brief overview of pore formation theory}

Although fundamentals of pore formation are not the focus of this review, we provide a brief summary. A number of exceptional publications ${ }^{31-35}$ have examined the mechanistic events leading to permeabilization in much more detail than offered here.

Biological membranes are organized into lipid bilayers (Fig. 1a). In aqueous solution, the amphiphilic fatty acids spontaneously form a membrane composed of two identical leaflets with opposite orientations since this is the most energetically favorable configuration. The outer face of either leaflet is composed of hydrophilic head groups that interact with the aqueous solution, whereas the innermost core is formed of hydrophobic tails. Physiologically, the lipid bilayer serves as a semipermeable barrier that separates the
FIG. 1. Pore formation is a stochastic process manifested in the lipid bilayer. The behavior of a cell exposed to an external electrical stimulus (a) depends on the amplitude and temporal characteristics of the field. Under physiological conditions (I), the lipid bilayer is a stable barrier exhibiting permeability only to select molecules. After exposure to an intense electric field, hydrophobic pores appear immediately (II) and stabilize after reorientation of lipid head groups (III), allowing for passage of previously impermeable molecules. The asymptotic model proposed by Neu and Krassowska $^{45}$ shows that (b) the free energy of induced pores decreases with increasing transmembrane potential beyond a critical radius. a
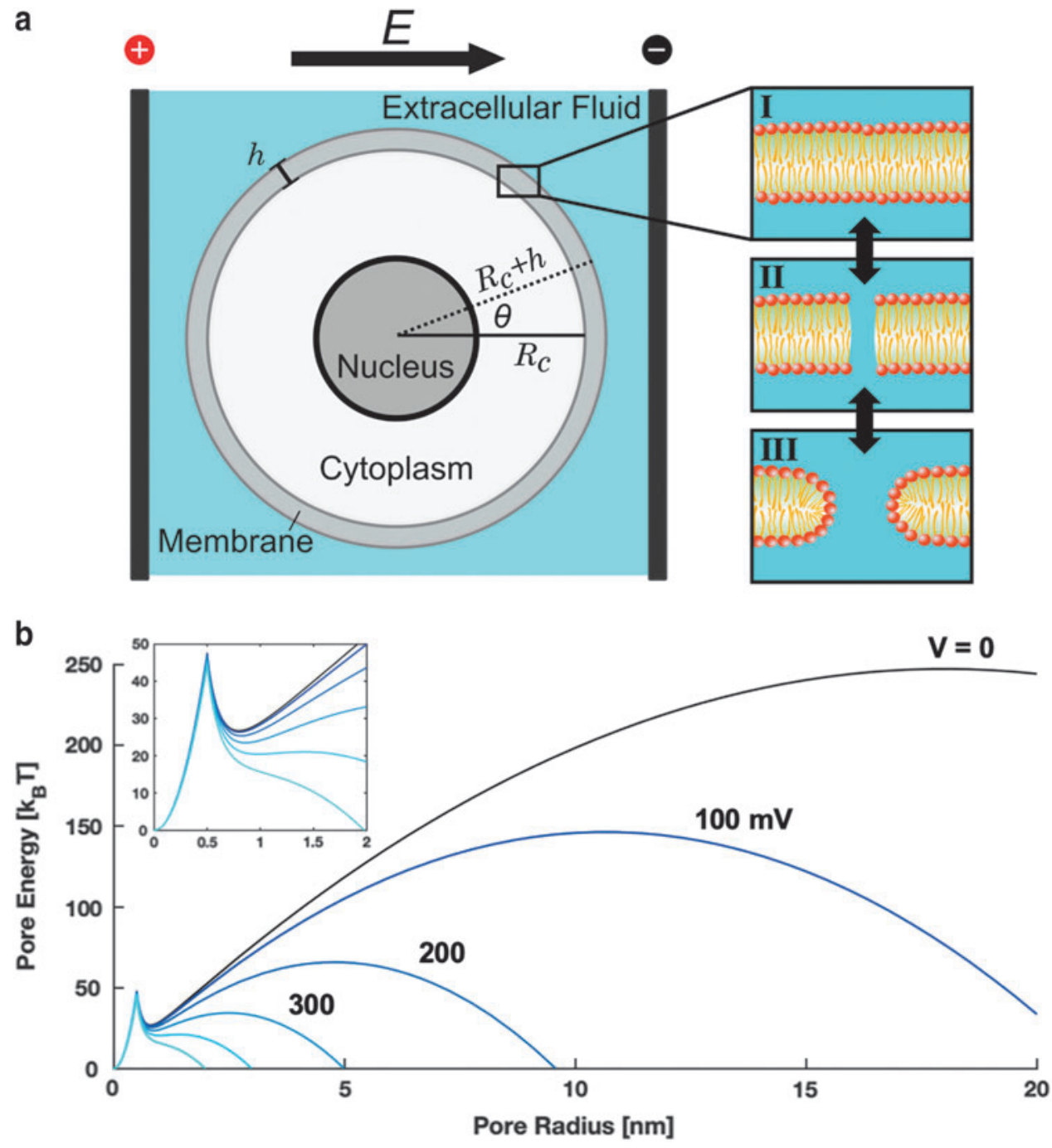
cytosol from extracellular fluid, only allowing diffusion of certain small uncharged and/or hydrophobic molecules. Large or charged molecules are transported through discrete transmembrane proteins organized into channels or pumps. Although the cell membrane is structurally stable, the fatty acids are held together by weak van der Waals forces, creating a "fluid-like" structure in which each fatty acid is constantly moving within the bilayer, mostly laterally within the same leaflet. This property gives the membrane the ability to allow passage of small molecules, to externalize proteins and waste, and to internalize molecules critical to intracellular processes.

The unique properties of the cell membrane allow aqueous pores to spontaneously form due to strong interactions between water molecules on either side, especially under environmental influences such as thermal fluctuations ${ }^{36,37}$ or mechanical insult. ${ }^{38}$ Although these nanopores can appear spontaneously, external electric fields (Fig. 1a) lower the activation energy necessary for the stochastic pore formation process, resulting in the production of pores at a higher rate. ${ }^{31}$

When the electrical stimulus is of sufficient strength, water dipoles on either side of the bilayer reorient to the field and their interaction becomes favorable. ${ }^{39}$ Initially, the water column spanning the membrane is highly unstable, forming hydrophobic pores or "water wires" (Fig. 1a-II). ${ }^{40}$ As electrical energy is delivered to the system and water molecules penetrate the membrane, many of the initial structures evolve into long-lived hydrophilic pores. ${ }^{41}$ This transition is mediated by reorientation of the polar fatty acid head groups into a more energetically favorable alignment, thereby stabilizing the pore. ${ }^{10,35,40}$ Simulations predict that hydrophobic pores are $<1 \mathrm{~nm}$ in diameter and reseal within milliseconds, whereas hydrophilic pores are roughly $1-10 \mathrm{~nm}$ in diameter and reseal within minutes to hours. ${ }^{33,35,41}$

\section{Mathematical determinants of pore formation}

Under physiological conditions, a biological cell will maintain an endogenous transmembrane potential (TMP), or resting potential, in which the inside of the cell has a slightly negative charge $(-50$ to $-90 \mathrm{mV}$ ) relative to its environment. Under an applied field, an induced TMP, $\Delta \Psi_{m}$, also arises across the membrane. Schwan was among the first to develop a mathematical description for $\Delta \Psi_{m} \cdot{ }^{42}$ Now bearing his name, this intuitive analytical equation assumes that the cell is isolated and has a spherical geometry with radius $R_{c}$ and membrane thickness $h$ (Fig. 1a). The steady-state equation is relevant for low-frequency pulses (pulse widths $>>1 \mu \mathrm{s})$ after the induced TMP has reached its maximum:

$$
\Delta \Psi_{m}(r, \theta)=\Delta \Psi_{m}\left(R_{c}, \theta\right)-\Delta \Psi_{m}\left(R_{c}+h, \theta\right)=f_{s} E R_{c} \cos \theta,
$$

where $E$ is the magnitude of the homogenous applied field, $\theta$ is the polar angle between the normal vector of the applied field and the site on the membrane at which $\Delta \Psi_{m}$ is evaluated, and $f_{s}$ is a dimensionless term relating the electrical properties of each component:

$$
f_{s}=\frac{3 \sigma_{e}\left[3 h R_{c}^{2} \sigma_{i}+\left(3 h^{2} R_{c}-h^{3}\right)\left(\sigma_{m}-\sigma_{i}\right)\right]}{2 R_{c}^{3}\left(\sigma_{m}+2 \sigma_{e}\right)\left(\sigma_{m}+\frac{1}{2} \sigma_{i}\right)-2\left(R_{c}-h\right)^{3}\left(\sigma_{e}-\sigma_{m}\right)\left(\sigma_{i}-\sigma_{m}\right)}
$$

In this equation, $\sigma_{i}, \sigma_{m}$, and $\sigma_{e}$ represent the conductivity of the cytosol, membrane, and extracellular fluid, respectively. To evaluate the transient behavior of the induced TMP, dielectric permittivity of the lipid bilayer $\left(\varepsilon_{m}\right)$ must be considered, and the equation is written as:

$$
\Delta \Psi_{m}(r, \theta, t)=f_{s} E R_{c} \cos \theta\left(1-e^{-t / \tau_{m}}\right) .
$$

This equation assumes that the intracellular and extracellular fluid permittivity is negligible. It is valid for sinusoidal fields with frequencies below $1 \mathrm{MHz}$ and rectangular pulses longer than $1 \mu \mathrm{s} .{ }^{43}$ In Equation (3), $\tau_{m}$ is the membrane charging constant given by:

$$
\tau_{m}=\frac{R_{c} \varepsilon_{m}}{2 h\left(\frac{\sigma_{i} \sigma_{e}}{\sigma_{i}+2 \sigma_{e}}\right)+R_{c} \sigma_{m}} .
$$

In many in vitro experiments, $f_{s}$ simplifies to 1.5 by assuming that the lipid bilayer is completely insulative (i.e., $\sigma_{m} \approx 0$ ), allowing one to easily estimate $\Delta \Psi_{m}$ for a specific experiment or treatment. The dependence of the TMP on $\theta$ results in a potential gradient with a maximum near $\theta=0$ and minima at the poles.

Mathematical descriptions of pore formation following the induced TMP have also been reported. The Smoluchowski diffusion equation provided the original framework for pore formation. ${ }^{44}$ This partial differential equation describes the flux, $S$, of pores in and out of the membrane as a function of time and pore radius:

$$
\mathrm{S}(t, r)=\frac{d N}{d t}-D\left(\frac{\partial N}{\partial r}+\frac{N}{k_{B} T} \frac{\partial U}{\partial r}\right)
$$

where $N$ is the pore density distribution function, $D$ is the diffusion constant of the pores, $U$ is the pore energy, $k_{B}$ is Boltzmann's constant, and $T$ is the absolute temperature. In 1999, Neu and Krassowska derived an asymptotic reduction of Equation (5) to an easily solvable ordinary differential equation. ${ }^{45}$ Briefly, a quadratic term was introduced to describe the formation of hydrophilic pores beyond a critical radius. For small hydrophilic pores, a Bessel function is used to explain expansion. The intercept of these two curves represents a local energy minimum indicated by the sharp peak at $r=0.5 \mathrm{~nm}$ in Figure 1b. In summary, the pore energy can be described as:

$U(r)=\left\{\begin{array}{lr}U_{*}\left(\frac{r}{r_{*}}\right)^{2}-\pi a_{p} r^{2} \Delta \Psi_{m}^{2}, & 0 \leq r \leq r_{*} \\ 2 \pi r \gamma-\pi r^{2} \Gamma-\pi a_{p} r^{2} \Delta \Psi_{m}^{2}+\left(\frac{C}{r}\right)^{4}, & r_{*} \leq r \leq h\end{array}\right.$,

where $U_{*}$ and $r_{*}$ are the critical energy and pore radius at the hydrophobic-hydrophilic transition, respectively; $\gamma$ is the line tension per unit length of pore perimeter; and $\Gamma$ is the surface tension per unit area of the intact membrane. The final quadratic term accounts for the steric repulsion between lipid heads lining the pore, where $C$ is a constant chosen to match empirical data. ${ }^{45-47}$ The term $\pi a_{p} r^{2} \Delta \Psi_{m}^{2}$ represents the capacitive contribution to the transition in which $a_{p}$ defines the dielectric permittivity of the porous membrane and is given 
as $\epsilon_{0}\left(\kappa_{w}-\kappa_{m}\right) / 2 h$. Here, $\epsilon_{0}$ is the dielectric permittivity of free space, and $\kappa_{w}$ and $\kappa_{m}$ are dielectric constants of water and the membrane, respectively. Figure $1 \mathrm{~b}$ illustrates the behavior of this system for different values of $\Delta \Psi_{m}$. Substituting Equation (6) into (5), rearranging, and simplifying with a number of assumptions, pore density $N(t)$ is approximated by:

$$
\frac{d N}{d t}=\alpha e^{\beta^{2}}\left(1-\frac{N}{N_{0}} e^{-q \beta^{2}}\right),
$$

in which $\alpha$ and $q$ are fitting parameters, $\beta$ is the ratio of $\Delta \Psi_{m}$ to the electroporation threshold $\Delta \Psi_{e p}$, and $N_{0}$ is the pore density when $\Delta \Psi_{m}=0 .{ }^{48}$ A summary of the parameters presented in these equations can be found in Table 1. A significant body of work has shown agreement between these equations and experimental observations. Furthermore, researchers are now able to directly utilize these simplified equations via analytical or numerical methods for experiment planning, protocol optimization, and data analysis.

\section{Electric field intensity, duration, and IRE}

Permeability increase, pore formation, and induced biological effects depend on applied parameters, such as the amplitude, number, and length of pulses. ECT treatments typically use eight pulses with electric field magnitudes near $1 \mathrm{kV} / \mathrm{cm} .{ }^{49}$ However, when a high number of pulses (60-100) of sufficient amplitude $(0.5-1.0 \mathrm{kV} / \mathrm{cm})$ are delivered, treated cells lose homeostatic equilibrium and die within minutes to hours. ${ }^{50}$ The exact mechanisms through which IRE causes cell death have not been fully elucidated, but a number of possible pathways such as direct electroconformational denaturation of macromolecules, ${ }^{51,52}$ induced depletion of adenosine triphosphate (ATP), ${ }^{53}$ local vascular disruptions, ${ }^{49,54}$ or electrolytic $\mathrm{pH}$ changes ${ }^{55}$ could contribute to cell injury.

Furthermore, it has been shown that $\mathrm{Na}^{+} / \mathrm{K}^{+}$pumps play a major role in restoring contractility after electroporation of skeletal muscle, supporting the theory that chemical imbalances mediate eventual cell death. ${ }^{56}$ Ultimately, high amounts of ATP are required to restore disrupted chemical concentration gradients; depending on the number and lifespan of the pores, this ATP demand can outweigh what can be generated by the cell, leading to high levels of intracellular $\mathrm{Ca}^{2+}$ and eventual cell death. ${ }^{57}$ Notably, the temporal scale in which IRE lesions appear seems to vary depending on the tissue type, suggesting a moiety of death mechanisms. ${ }^{58}$ Future work evaluating these mechanisms more rigorously will be vital to our understanding of IREinduced cell death.

The application of an electric field across a dielectric material—such as biological matter (cells/tissue)—results in resistive losses and subsequent generation of heat. Thus, supplying excessive electrical energy within a given time frame can cause thermal damage. ${ }^{14,59,60}$ This side effect can be alleviated by referencing the literature to use previously determined nonthermal parameters for specific tissues, by incorporating thermal mitigation strategies, or by modeling treatment beforehand to select pulse paradigms capable of nonthermal IRE. ${ }^{61}$

Table 1. Summary of Parameters Used in Basic Transmembrane Potential AND PORE Formation Equations (AdAPTEd FROM SWEENEY ${ }^{147}$ )

\begin{tabular}{|c|c|c|c|c|}
\hline Symbol & Definition & Value or range & Units & Source \\
\hline$R_{c}$ & Radius of a mammalian cell & $5-50$ & $\mu \mathrm{m}$ & - \\
\hline$k_{B}$ & Boltzmann constant & $1.380649 \times 10^{-23}$ & $\mathrm{~J} / \mathrm{K}$ & - \\
\hline$T$ & Temperature & 295 & $\mathrm{~K}$ & - \\
\hline$\sigma_{e}$ & Extracellular fluid conductivity (saline) & 1.6 & $\mathrm{~S} / \mathrm{m}$ & - \\
\hline$\epsilon_{0}$ & Dielectric permittivity of vacuum & $8.85 \times 10^{-12}$ & $\mathrm{~F} / \mathrm{m}$ & - \\
\hline$h$ & Lipid bilayer thickness & $3-15$ & $\mathrm{~nm}$ & $\begin{array}{c}\text { DeBruin and Krassowska, } \\
\text { Kotnik and Miklavcic } \\
{ }^{448}\end{array}$ \\
\hline$\sigma_{i}$ & Cytosol conductivity & $0.1-1$ & $\mathrm{~S} / \mathrm{m}$ & $\begin{array}{c}\text { DeBruin and Krassowska, } \\
\text { Kotnik and Miklavcic }{ }^{448}\end{array}$ \\
\hline$\sigma_{m}$ & Lipid bilayer conductivity & $10^{-10}$ to $8.7 \times 10^{-6}$ & $\mathrm{~S} / \mathrm{m}$ & $\begin{array}{l}\text { Gascoyne et al. }{ }^{149} \text { Hu et al., }{ }^{150} \\
\text { Smith et al. }\end{array}$ \\
\hline$\varepsilon_{m}$ & Lipid bilayer dielectric permittivity & $4.4 \times 10^{-11}$ & $\mathrm{~F} / \mathrm{m}$ & Smith et al., ${ }^{151}$ Ye et al. ${ }^{152}$ \\
\hline$\tau_{m}$ & Membrane charging constant & $0.1-1$ & $\mu \mathrm{s}$ & $\begin{array}{l}\text { Weaver and Chizmadzhev, } \\
\text { Vasilkoski et al. }{ }^{153}\end{array}$ \\
\hline$D$ & Diffusion constant of pores & $5 \times 10^{-14}$ & $\mathrm{~m}^{2} / \mathrm{s}$ & Neu and Krassowska ${ }^{45}$ \\
\hline$U_{*}$ & Pore energy at transition & 45 & kT & Neu and Krassowska ${ }^{45}$ \\
\hline$r_{*}$ & Pore radius at transition & $0.5-0.8$ & $\mathrm{~nm}$ & $\begin{array}{l}\text { Neu and Krassowska, } \\
\text { Smith et al. }{ }^{451}\end{array}$ \\
\hline$\gamma$ & Normalized line tension of pore perimeter & $1.8 \times 10^{-11}$ & $\mathrm{~J} / \mathrm{m}$ & Neu and Krassowska ${ }^{45}$ \\
\hline 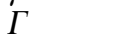 & Normalized surface tension of membrane & $10^{-3}$ & $\mathrm{~J} / \mathrm{m}^{2}$ & Neu and Krassowska ${ }^{45}$ \\
\hline$C$ & Quadratic fitting parameter & $9.67 \times 10^{-15}$ & $\mathrm{~J}^{1 / 4} \mathrm{~m}$ & Neu and Krassowska ${ }^{45}$ \\
\hline$a_{p}$ & Permittivity constant & $6.9 \times 10^{-2}$ & $\mathrm{~F} / \mathrm{m}^{2}$ & Neu and Krassowska ${ }^{45}$ \\
\hline$\kappa_{w}$ & Dielectric constant of water & 80 & - & Neu and Krassowska ${ }^{45}$ \\
\hline$\kappa_{m}$ & Dielectric constant of membrane & 2 & - & Neu and Krassowska ${ }^{45}$ \\
\hline$N_{0}$ & Equilibrium pore density & $1.5 \times 10^{5}$ & $\mathrm{~cm}^{-2}$ & Debruin and Krassowska ${ }^{46}$ \\
\hline$\Delta \Psi_{e p}$ & Characteristic voltage of electroporation & 258 & $\mathrm{mV}$ & Debruin and Krassowska 46 \\
\hline$\alpha$ & Fitting parameter & 100 & $\mathrm{~cm}^{-2} \mathrm{~ms}^{-1}$ & Debruin and Krassowska ${ }^{46}$ \\
\hline$q$ & Fitting parameter & 2.46 & - & Debruin and Krassowska ${ }^{46}$ \\
\hline
\end{tabular}




\section{Basics of tissue ablation with IRE}

IRE is typically performed as a minimally invasive percutaneous or laparoscopic procedure. Patients are sedated with general anesthesia, and neuromuscular blocking agents are prophylactically administered to mitigate muscle contractions that can occur due to electrical stimulation of nearby neurons. Although flat plate and endoscopic electrodes have been used, electrical energy is typically supplied through parallel needle electrodes $(\varnothing \sim 1 \mathrm{~mm})$ inserted directly into the tissue of interest (Fig. 2). Depending on the size of the lesion, IRE is performed with as little as two or up to six monopolar probes. Additionally, a single-insertion bipolar probe has been reported for certain small tumors in precarious locations. After insertion, probe locations can be verified via intraoperative imaging (ultrasound or computed tomography $[\mathrm{CT}]$ ), and 50-100 pulses on the order of $100 \mu \mathrm{s}$ in length are sequentially delivered between each electrode pair. IRE is synchronized with the absolute refractory period of the electrocardiogram (ECG) to mitigate the risk of electrical interference with cardiac myocytes and potential arrhythmia. $^{62}$

The electric field distribution in the tissue drives treatment outcome - this is dictated by a variety of factors including electrode geometry/configuration, pulse parameters, and tissue properties. Important tissue-specific parameters pertaining to the production of nonthermal ablation are the dynamic electrical conductivity and lethal electric field threshold. ${ }^{63}$ Dynamic conductivity describes the evolution of the tissue's electrical conductivity when exposed to electric fields of increasing amplitude and can be determined through carefully planned experiments. ${ }^{63,64}$ The lethal threshold is a metric of the susceptibility of a certain tissue or cell type to IREinduced cell death. It is dependent on the shape and amplitude of the characteristic waveform, number of pulses, and duration of the applied field, but for most tissues, this threshold is between 300 and $1000 \mathrm{~V} / \mathrm{cm}$ when 100 pulses are applied. ${ }^{65}$

It is critical to note that the electric field threshold for a given tissue decreases as more pulses are applied but saturates after a certain number of pulses. Moreover, because minor Joule heating effects occur during treatment, increased pulse numbers result in local increases in conductivity at a rate of $1-3 \%$ per degree Celsius, which can also propagate the electric field and increase ablation volume. However, because IRE outcomes are heavily dependent on user inputs as well as characteristic properties of the tissue under study, the framework by which lethal thresholds are calculated must be taken into careful consideration. The minimum parameters that should be reported after IRE treatment are the number of pulses, pulse width $(\mu \mathrm{s})$, frequency $(\mathrm{Hz})$, and voltage-todistance ratio (VDR, V/cm) — defined as the quotient of the applied potential $(\mathrm{V})$ and electrode separation $(\mathrm{cm})$. These allow one to gauge the intensity of treatment and provide a basic level of standardized reporting.

Preclinical investigations of IRE often employ pretreatment planning tools to study the outcomes of certain pulse paradigms. Such models allow for the development of personal treatment plans for each patient, ensuring accurate probe placement, complete tumor coverage, and minimal temperature rise. ${ }^{66,67} \mathrm{~A}$ brief example of the treatment planning process can be seen in Figure 3. In the future, such planning modules will likely become a mainstay of human treatments, but no clinically accepted modeling procedure/ algorithm has been introduced thus far.

\section{IRE as a Monotherapy}

Since its introduction in 2005, more than 50 clinical trials have been organized to study IRE (Fig. 4) and hundreds of articles demonstrating clinical outcomes have been published. IRE has helped more than 5500 patients with unresectable cancer, many of whom have participated in these trials. In subsequent sections, we review the major in vivo work and clinical studies that provide insight regarding the uses and outcomes of IRE. While we acknowledge many studies that have investigated IRE in the lung, kidney, brain, and other organ systems, we maintain a focus on the prostate, pancreas, and liver, as cancers in these locations pose specific opportunities that IRE can potentially address.

\section{Prostate}

Prostate cancer $(\mathrm{PCa})$ is the most common neoplasm in men, accounting for one in five new cancer cases. ${ }^{68} \mathrm{Al}-$ though patients diagnosed with PCa have 5-year survival rates of nearly $100 \%$, this disease is the second most deadly cancer in the male population. ${ }^{69}$ Available interventions including radical prostatectomy and radiotherapy tend to have negative consequences on sexual and urinary function $^{70}$; thus, focal ablation has emerged as a viable alternative. IRE is particularly promising for patients with $\mathrm{PCa}$ due to fact that roughly $80 \%$ of these patients exhibit localized disease. ${ }^{71}$ Additionally, IRE may improve functional outcomes for PCa patients due to the presence of protein-rich structures near the prostate, including the neurovascular bundle, lower urinary sphincter, ejaculatory vesicles, and urethra-all of which are at risk when patients undergo resection or thermal ablation.

The first evaluation of IRE in the prostate was performed by Onik et al. in $2007 .^{22}$ In this initial study, six healthy canine prostates were treated with IRE using VDRs up to $3000 \mathrm{~V} / \mathrm{cm}$. The urethra was spared even when purposefully

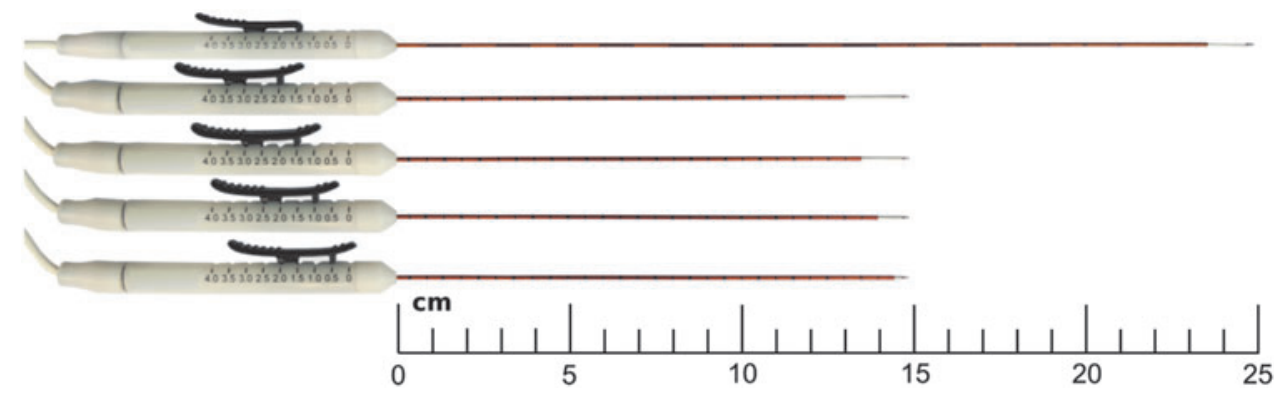

FIG. 2. IRE is delivered through 25 - or $15-\mathrm{cm}$ long monopolar electrodes with varying degrees of exposure. IRE, irreversible electroporation. 


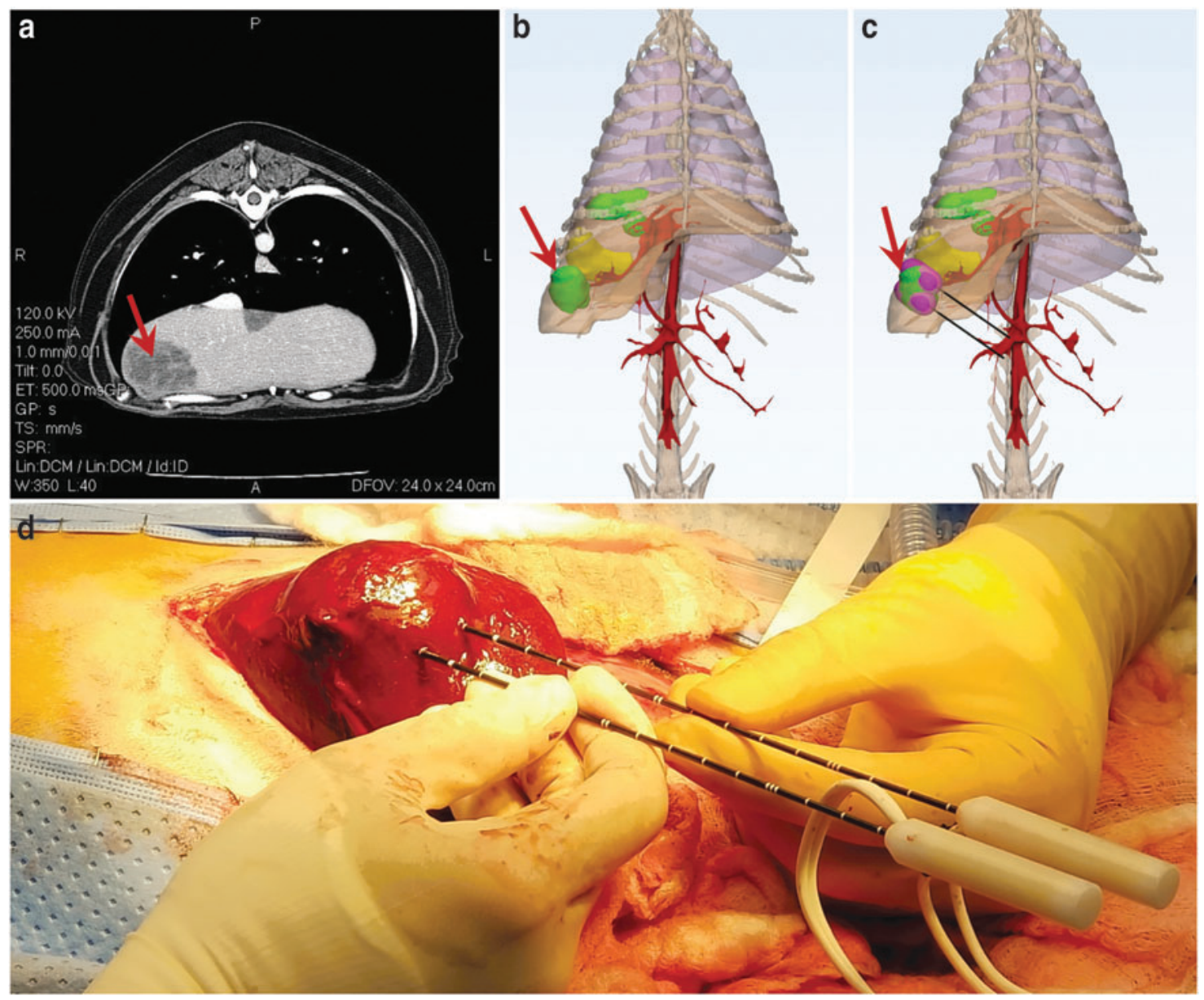

FIG. 3. Pretreatment planning allows for prediction of ablation outcomes. For a canine case of multifocal liver cancer, this consists of (a) locating malignant tissue (red arrow) on diagnostic imaging, (b) reconstructing patient anatomy to assess tumor proximity to relevant structures, (c) identifying suitable electrode insertion pathway and estimating ablation volume (pink), and (d) using the pretreatment planning model to inform insertion tracts for optimal ablation outcomes.

ablated, and although necrosis was noted on directly ablated vessels, patency was maintained without evidence of thrombosis. In a follow-up study, Onik and Rubinsky evaluated early safety and efficacy of IRE in 16 human patients. ${ }^{72}$ At 3 weeks post-IRE, 93\% of biopsies were negative and potency was preserved in all men potent before treatment. Subsequent reports sought to elaborate on these early find- ings. In 2013, Tsivian and Polascik performed bilateral ablations in the healthy prostate of 12 dogs and confirmed the ability of IRE to spare the urethra, rectum, and capsule when probes were placed in close vicinity $(\sim 7 \mathrm{~mm})$ to these structures. ${ }^{73}$ Additionally, no clinically significant side effects were observed and erectile function was maintained in all dogs.

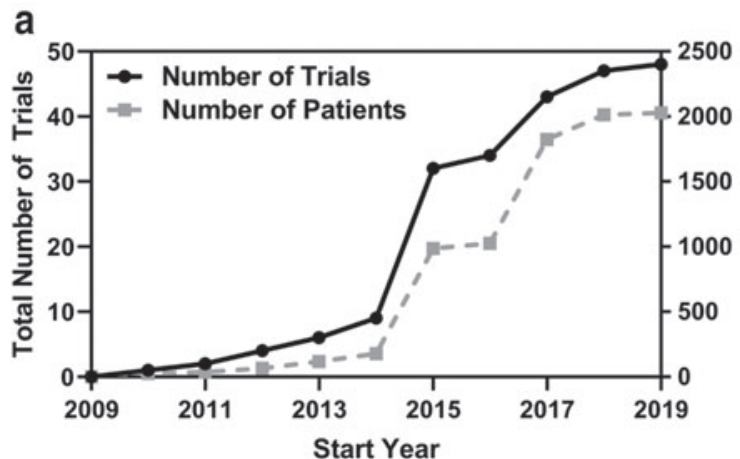

b

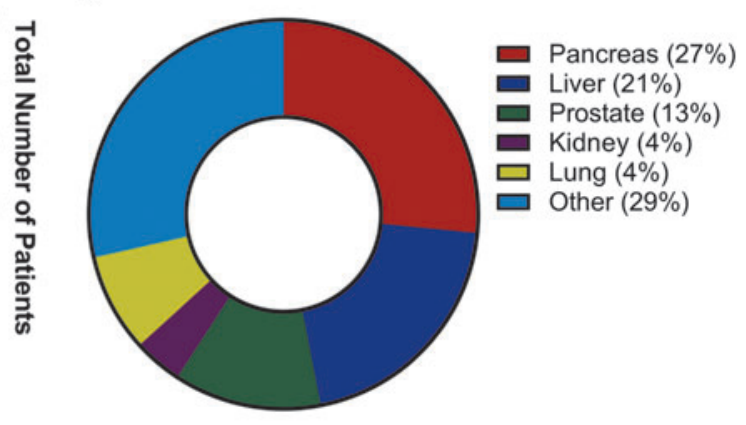

FIG. 4. (a) Temporal trends in the cumulative number of interventional clinical trials investigating IRE and the corresponding number of patients associated with them. (b) Distribution of clinical trials based on cancer localization. Data acquired from ClinicalTrials.org on August 31, 2019. 


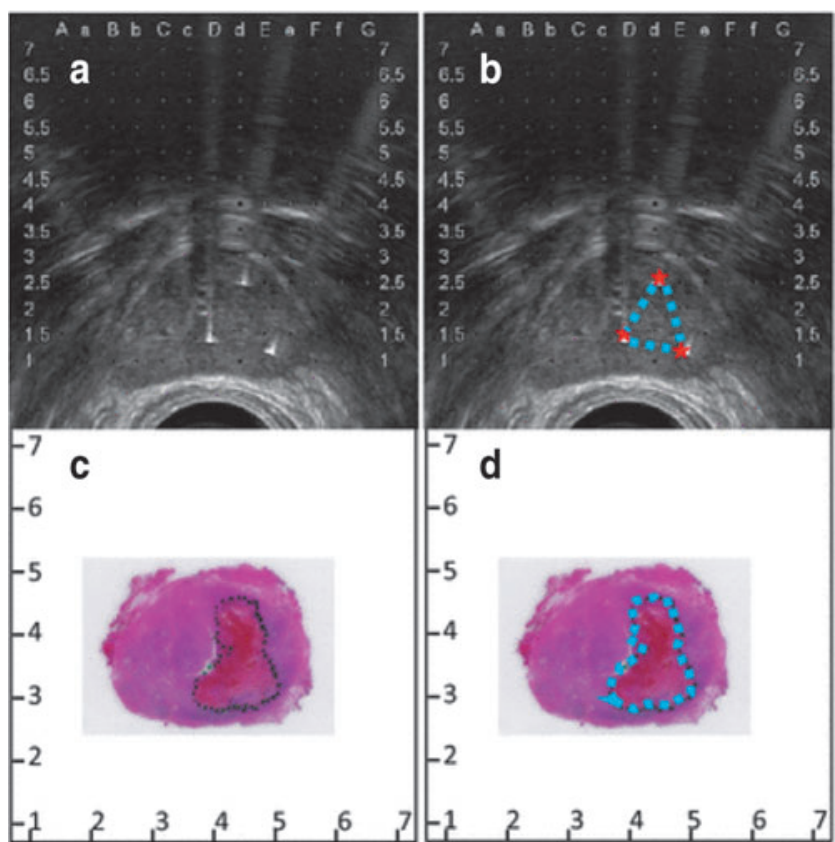

FIG. 5. Ablation regions visualized on transrectal ultrasound correlate with those quantified histologically. (a) Perioperative ultrasound shows (b) the area circumscribed by the electrode configuration within the hypoechoic prostatic tissue. (c) Histology obtained after radical prostatectomy 4 weeks post-treatment shows (d) the area of ablation, which closely resembles the size, shape, and location of that visualized intraoperatively. Image originally found in van den Bos et al. ${ }^{77}$ reprinted under Creative Commons Attribution 4.0 International License.

The first report evaluating intermediate-term safety and feasibility in humans was published shortly thereafter. ${ }^{74}$ In this study, IRE was performed in 34 men with localized PCa. At a median follow-up of 6 months, potency and continence were preserved in $95 \%$ and $100 \%$ of men potent/continent before the study. From an oncological perspective, six patients had suspicious residual disease and one local failure was recorded. In 2015, a series of investigations evaluating quality of life (QoL), ${ }^{75}$ histopathological outcomes, ${ }^{76}$ and effects of electrode configuration on ablation outcomes ${ }^{77}$ were published on a 16-patient cohort that underwent IRE ablations followed by radical prostatectomy 4 weeks later. Here, it was shown that the mild adverse events resulting from IRE were mostly resolved by the 4-week time point. Slight declines were noted in urinary QoL while functional outcomes were retained. Histologically, sharp demarcations between ablated and viable tissue were noted, and they correlated well with the hypointense region seen on transrectal ultrasound (Fig. 5). Finally, it was found that a higher number of electrodes produced a larger ablation relative to the area circumscribed by the electrode configuration. ${ }^{77}$

A number of other clinical studies have since evaluated IRE outcomes for the ablation of PCa (Table 2). Recently, two larger patient cohorts have been assessed. In the first, safety, QoL, and short-term oncological outcomes were evaluated by van den Bos et al. ${ }^{78}$ Safety was again demonstrated while oncological control was $84 \%$ in-field and $76 \%$ whole-gland. The authors noted that after gaining experience with the procedure, margins were increased and NanoKnife ${ }^{\circledR}$ operation became more efficient; oncological control with increased margins in the absence of system errors increased to $97 \%$ and $87 \%$, respectively. The latter study by Guenther et al. was a retrospective analysis of longer term outcomes for 429 patients. $^{79}$ This cohort was made up of patients with high-risk disease $(73 \%)$, but 5-year recurrence rates were similar to that of radical prostatectomy at roughly $10 \%$. Furthermore, IRE maintained urogenital function, including complete preservation of urinary continence, while only $3 \%$ of patients experienced erectile dysfunction 12 months after treatment. Although further randomized evaluations are necessary, these results support the safety and feasibility for treatment of patients with localized $\mathrm{PCa}$, especially those with disease that is recurrent and/or not amenable to surgery/ radiation.

\section{Pancreas}

So far, unresectable pancreatic tumors present perhaps the largest window of opportunity for IRE as a technique capable of drastically improving clinical outcomes. Patients with pancreatic cancer have extremely low 5-year survival $(9 \%),{ }^{68}$ and less than $20 \%$ are candidates for surgery. ${ }^{80}$ The pancreas is situated near the celiac trunk, hepatic artery, and superior mesenteric vessels, contributing to its surgical inaccessibility (Fig. 6). Thermal ablation is associated with high morbidity when applied to pancreatic tumors due to the presence of these fragile structures. ${ }^{81}$ Thus, IRE is an emerging tool that could play a critical role in the future management of patients with locally advanced disease.

To date, roughly 30 articles have evaluated IRE in vivo for focal ablation of pancreatic tissue. The first of these was performed by Charpentier et al. in swine. ${ }^{82}$ The authors of this study used two monopolar needle electrodes with an induced voltage of $1500 \mathrm{~V}$ and spacing of $10-15 \mathrm{~mm}$ to ablate healthy pancreas. All pigs tolerated the procedure without complication and pancreatic ducts were preserved. Bower et al. published a similar study shortly thereafter, confirming the preservation of vascular structures and reporting the feasibility of both monopolar and bipolar IRE probes for pancreatic ablations. $^{23}$ The first clinical study of pancreatic IRE was performed by Martin et al. in 2012. ${ }^{83}$ Here, 27 patients with locally advanced pancreatic adenocarcinoma (LAPC) were treated with IRE at a target VDR of $1500 \mathrm{~V} / \mathrm{cm}$. One hundred percent ablation success was achieved with only four potential IRE-related adverse events, and no evidence of recurrence was observed within the 90-day follow-up period. In a similar study, Narayanan et al. performed the first percutaneous IRE treatments in a cohort of patients with unresectable or metastatic disease under CT guidance. ${ }^{84}$ Of the 15 patients, 2 were downstaged and underwent marginnegative resection. In the remaining 13 patients, $46 \%$ had stable disease at last follow-up. In 2015, Martin et al. published a study evaluating IRE in 150 patients with LAPC. ${ }^{85}$ Patients receiving treatment with IRE had an overall survival of 18 months and local progression-free survival of 10.7 months. Including another 50 patients in whom IRE was used for margin accentuation, overall survival for the 200-patient cohort was 24.9 months.

In recent years, IRE has been associated with overall survival of up to 27 months for patients with unresectable 


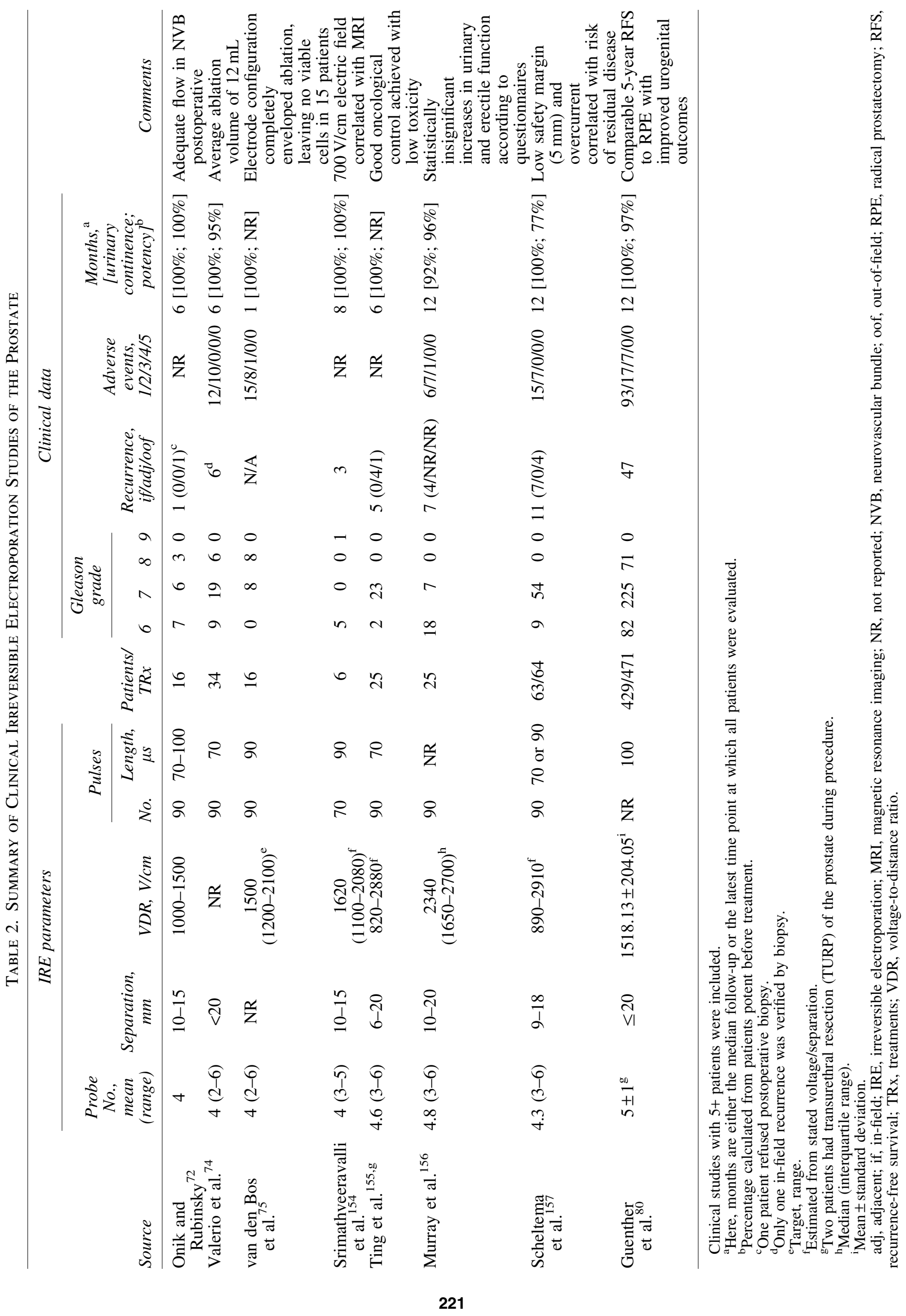


LAPC, ${ }^{86}$ and response rates commonly exceed $70 \% .{ }^{87-89}$ In addition to potential survival improvements, some patients have been able to lower narcotic intake ${ }^{83}$ after treatment and others have shown major improvements in QoL. ${ }^{89}$ Depending on the extent of vascular involvement, downstaging occurs in $5-10 \%$ of cases, allowing for follow-up resection. ${ }^{86,90,91}$ Despite the promising results reported in some studies, a limited number of institutions have adopted IRE (Table 3). This could be due to inherent difficulties in treating advanced pancreatic tumors, discrepancies in patient selection, and differences in institutional protocols for IRE application. Moreover, postoperative imaging has proven more difficult for assessing ablation outcomes for pancreatic lesions, which could contribute to these inconsistent findings. ${ }^{93}$ Although many studies have reported prolonged survival after IRE, future randomized studies are critically needed to directly compare the safety and efficacy of IRE against alternative treatments.

\section{Liver}

Hepatocellular carcinoma (HCC) represents the vast majority of liver malignancies and is the third most common cause of cancer-related mortality. ${ }^{94}$ When detected early, curative treatment for $\mathrm{HCC}$ can be achieved with resection or transplantation, but less than $15 \%$ of patients fall into this category. ${ }^{95}$ The liver is also frequently a site of metastasis, especially for primary tumors of the gastrointestinal tract. Focal thermal ablation has become a mainstay in the management of liver lesions and has shown similar oncological outcomes to resection with limited complications and without reducing transplant exception points. ${ }^{96,97}$ Despite this, thermal ablation is often not an option due to the presence of tumors on or near hepatic blood vessels or biliary structures, and patients with underlying liver dysfunction have increased rates of post-treatment abscess formation after thermal ablation. ${ }^{98}$ The nonthermal nature of IRE allows it to overcome many of these limitations, and its role in the management of hepatic masses is still being fully established.

The first in vivo study of IRE for liver ablation used flat plate electrodes and a single, $20 \mathrm{~ms}$ monopolar pulse with $1 \mathrm{kV} / \mathrm{cm}$ amplitude to create reproducible regions of "endothelial necrosis, thrombus formation, vascular compromise, and vacuolar degeneration" within $3 \mathrm{~h}$ of treatment in rats. ${ }^{18}$ Shortly after this publication, needle electrodes were used to generate ablations in a large animal model, ${ }^{20}$ and the ability to perform percutaneous IRE in the liver and observe ablation in real time via ultrasound was demonstrated. ${ }^{19}$

These early findings were first translated to the clinic when Thomson et al. found IRE to have an acceptable safety profile for the ablation of the liver, kidney, and lung tumors, including metastases from primary tumors elsewhere in the body. ${ }^{99}$ In several subsequent studies, IRE was shown to be suitable for ablating tumors near vital hepatic structures. ${ }^{100-104}$ The ability to treat these tumors has opened the door to many clinical investigations (Table 4). Some of these reports have investigated functional deficits following IRE and have found that biomarkers of hepatic function tend to rise transiently (1-2 days) but return to baseline within a few days, verifying safety. ${ }^{103,105}$ Notably, Bhutiani et al. found that IRE had a similar 6-month success rate but was more tolerable than microwave ablation for patients with compromised liver function (Child-Pugh B). ${ }^{106}$ IRE-treated patients also had shorter hospital stays and lower rates of re-admission, likely due to lower indiscriminate effects on hepatic tissue.

In recent years, reports with intermediate to long-term follow-up have shown that IRE produces acceptable oncological outcomes for patients with unresectable disease, especially for small tumors. ${ }^{107,108}$ For tumors larger than 2$4 \mathrm{~cm}$, overall and recurrence-free survival tend to decline, but modifications to the treatment paradigm in the future may allow for higher efficacy in larger lesions. ${ }^{109}$ Besides large tumors, the only other major contraindication for performing hepatic IRE is the presence of metallic implants in close proximity to the tumor, which has been shown to adversely affect progression-free survival. ${ }^{110}$ Varying degrees of complication have been observed with IRE in liver tumors, ${ }^{100,103,108}$ likely due to the learning curve inherent in the adoption of this new treatment modality. ${ }^{111}$ In recent retrospective analyses, however, the overall complication rate of hepatic IRE was similar to thermal ablation despite being used as a salvage therapy in many cases of advanced disease. ${ }^{112,113}$ In summary, IRE appears to be a promising option for precarious, central hepatic tumors abutting proteinaceous structures such as the biliary tree or portal vein, but again, randomized studies are needed to further delineate its oncological outcomes in comparison to existing focal therapies.

\section{Alternative Applications and Future Directions}

\section{Cardiovascular}

IRE may be a useful addition to the technological repertoire for cardiac ablation and other vascular applications where focal destruction of aberrant cells is desired, namely in conditions such as atrial fibrillation, restenosis, and resistant hypertension. Although it was first noted that intense electric fields arising during defibrillation may create "sarcolemmal microlesions", in 1987, ${ }^{114}$ IRE was not intentionally pursued for clinical cardiovascular applications until the pioneering work of Maor and Rubinsky appeared in the late 2000s. ${ }^{15,115,116}$

Early investigations applied IRE to rat carotid arteries and demonstrated ablation of vascular smooth muscle cells (VSMCs) without complication and without macroscopic damage to acellular vascular architecture ${ }^{15}$ using a wide range of pulse parameters. ${ }^{117}$ Later reports showed that VSMCs are eliminated over the course of $72 \mathrm{~h}$ without injury to elastic lamella, collagen fibers, or proteoglycans, and endothelial cells regenerated by 7 days. ${ }^{118}$ IRE has also been shown to mitigate restenosis following angioplasty, ${ }^{119}$ and custom devices capable of endovascular pulse delivery have been developed. ${ }^{120}$ Although not covered in depth here, these findings led to a series of articles investigating the use of IRE as a tissue decellularization technique, which was initially demonstrated both in situ and ex vivo. ${ }^{118,121}$

Lavee et al. were the first to use IRE to correct arrhythmogenic regions of the heart. Schemes using between 8 and 32 pulses generated completely transmural, epicardial atrial ablations in swine. ${ }^{122}$ Circular ablation catheters were introduced by Wittkampf et al. and were shown to safely generate clinically relevant lesions in pulmonary vein (PV) ostia $^{123}$ and venricles. ${ }^{124}$ Van Driel et al. demonstrated a 


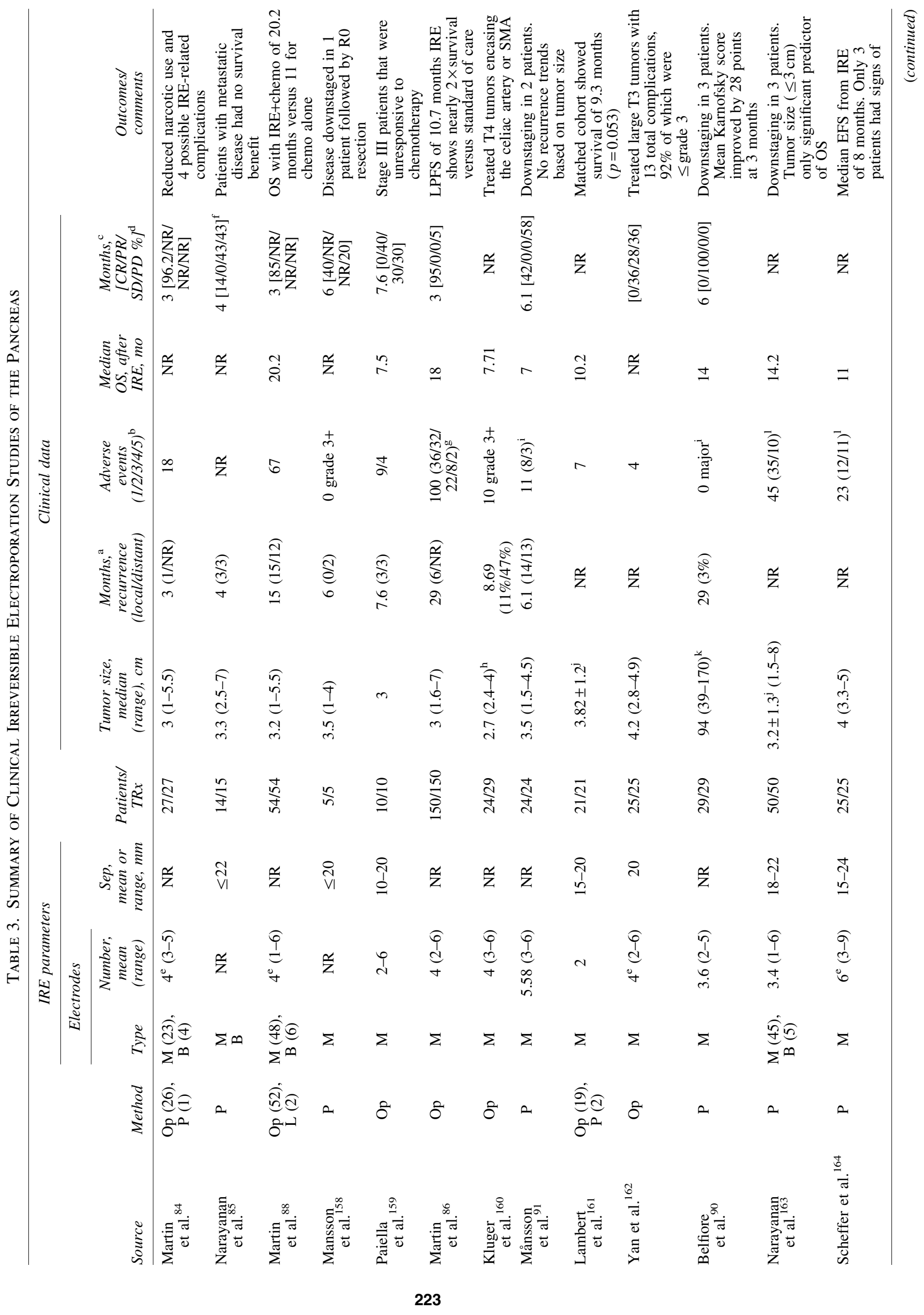




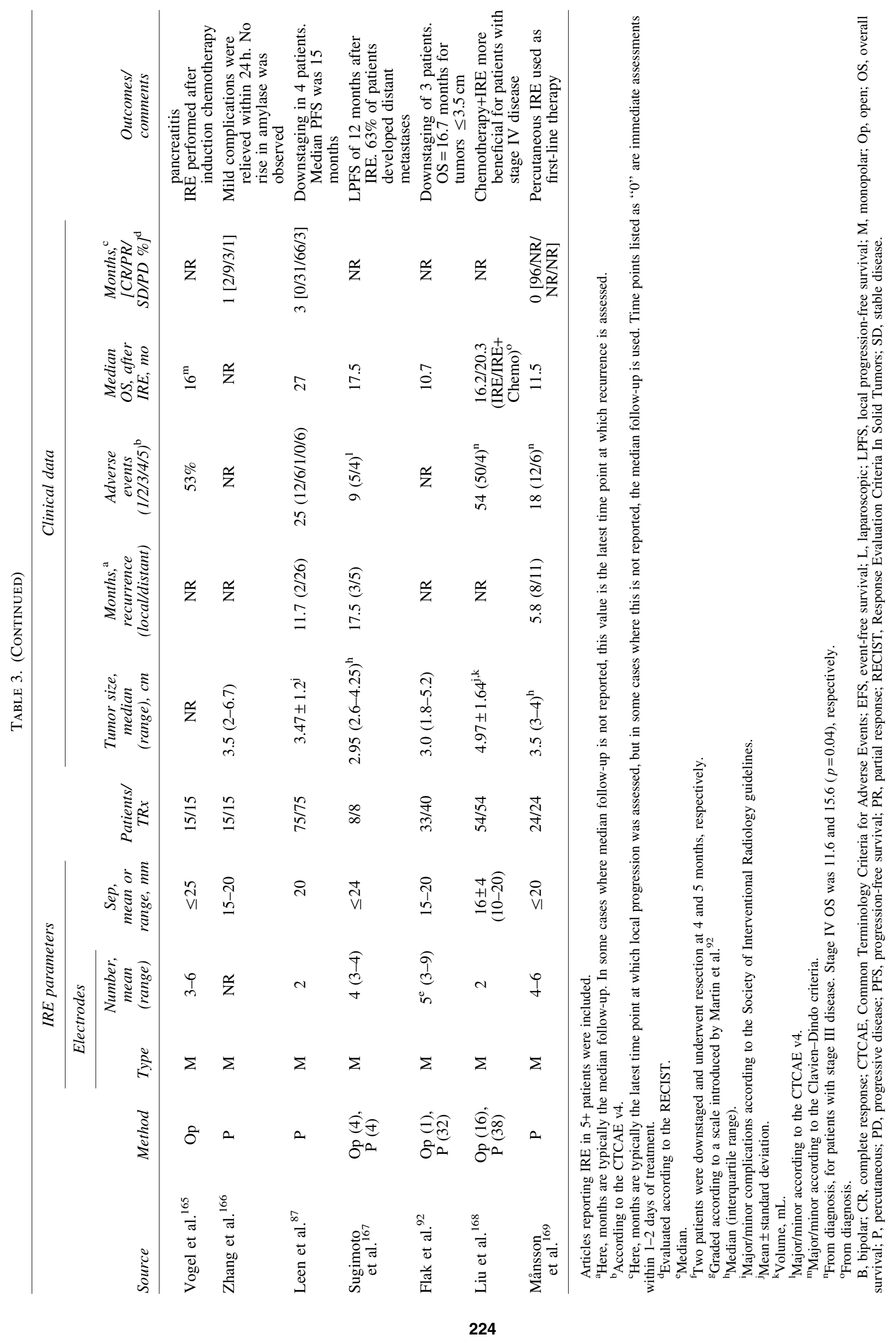




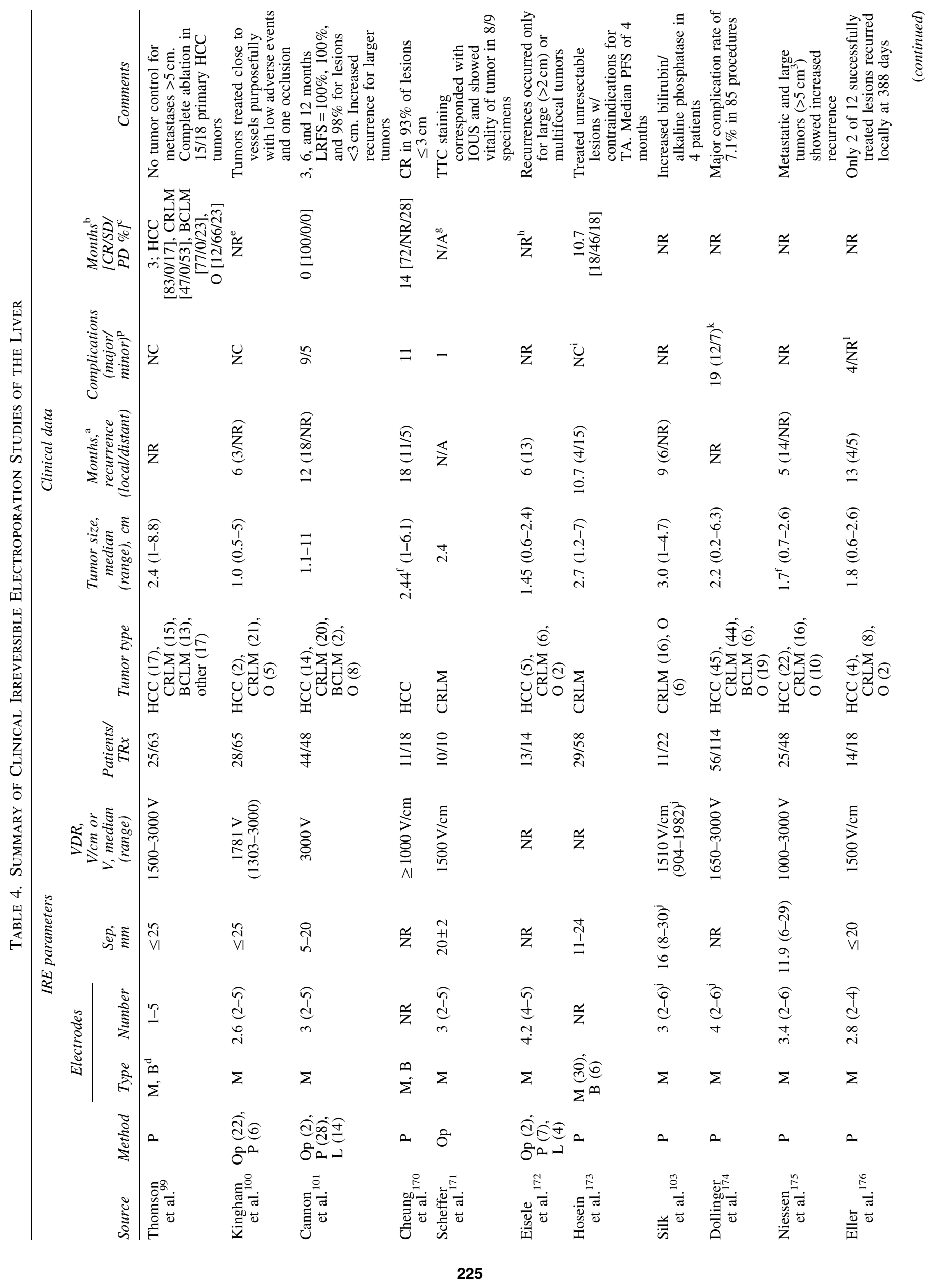




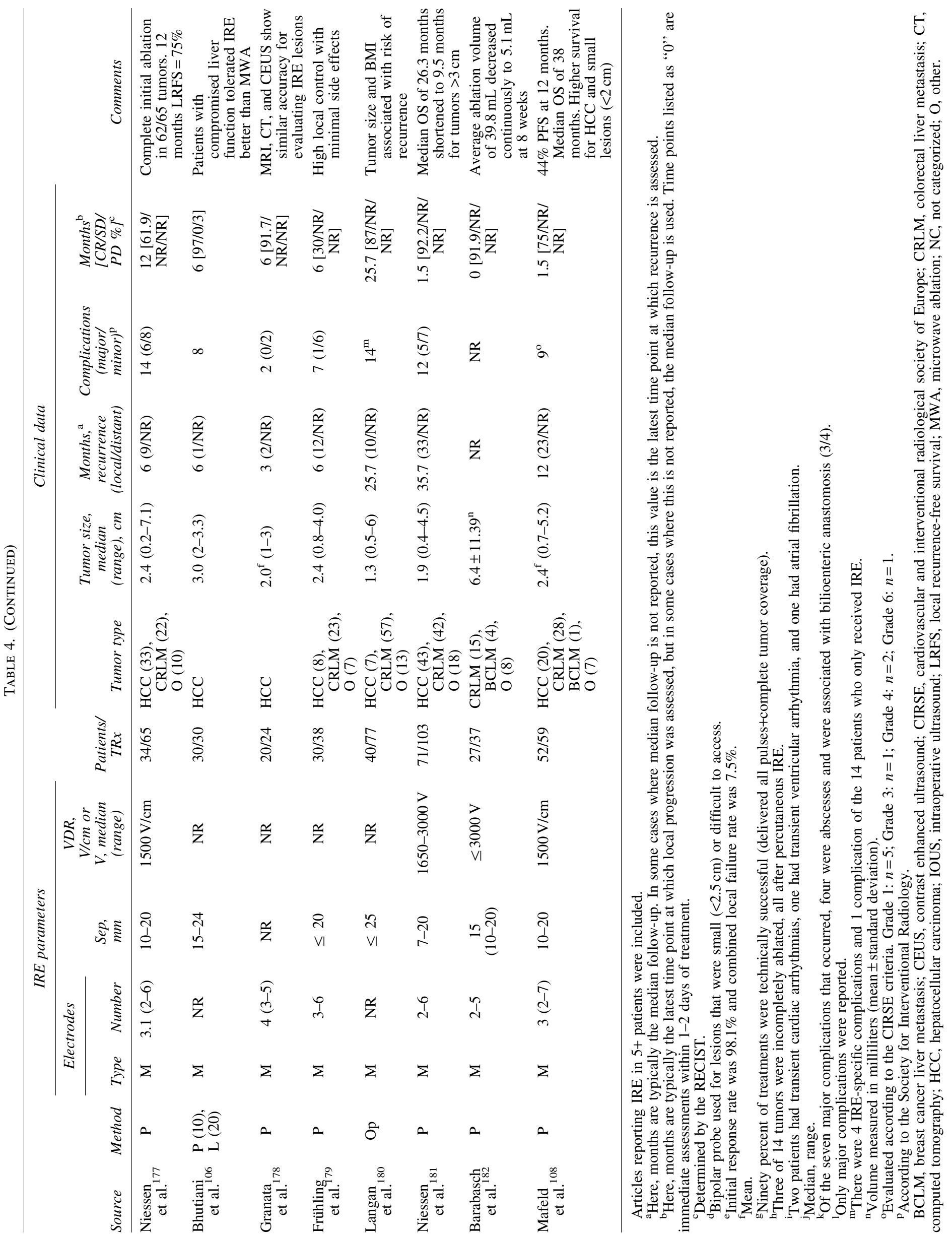


reduction in PV stenosis after catheter-based IRE versus radiofrequency ablation, ${ }^{125}$ and a later study demonstrated similar PV ablations with a commercially available catheter in canines. ${ }^{126}$ Other relevant work has shown that IRE can be used to ablate Purkinje fibers ex vivo and reduce vulnerability to ventricular fibrillation. ${ }^{127}$ Finally, one human study has been performed in which IRE was used successfully to electrically isolate PVs in 22 patients. ${ }^{128}$ Ablation times were less than $1 \mathrm{~min}$, and 1-month follow-up visits indicated uneventful recovery. These emerging data support the further exploration of IRE for cardiovascular applications.

\section{Immune modulation and synergy with immunotherapy}

Recently, the ability of focal tumor therapies to elicit systemic immune activation has garnered much attention. Immune modulation in response to IRE treatment has been investigated in a number of in vitro and in vivo studies. The first of these showed a decline in immune cell populations$\mathrm{CD}^{+}$and $\mathrm{CD}^{+} \mathrm{T}$ lymphocytes, antigen-presenting cells, macrophages, and natural killer (NK) cells-over the course of $6 \mathrm{~h}$ after IRE treatment, indicating the ability of IRE to form substantial ablations without relying on antitumor immunity. ${ }^{129}$ A more comprehensive study evaluating immune cell populations and cytokines produced up to 21 days after treatment in an immune-competent rat osteosarcoma model found significantly increased $\mathrm{CD}^{+}$and $\mathrm{CD} 4^{+} \mathrm{T}$ lymphocytes, a higher $\mathrm{CD}^{+} / \mathrm{CD}^{+}$ratio, and modified cytokine expression in IRE versus sham and surgery control groups. ${ }^{130}$

It was later shown that immunocompetent mice have a better local response to IRE and improved survival versus their immunodeficient counterparts. ${ }^{131}$ Furthermore, recent in vitro work has shown that melanoma cells ablated with IRE release substantially more protein and TRP-2 antigen than those treated with thermal ablation (heating and cryoablation). ${ }^{132}$ Additional analyses showed that protein released from IRE-treated cells was more efficient at inducing $\mathrm{T}$ cell proliferation than that released from heat- or cryotherapytreated cells, supporting the observation that IRE reduces the rate of metastases in a rabbit VX2 model $^{133}$ and exhibits a stronger abscopal effect than thermal ablation. ${ }^{134}$ Improved immune response versus other modalities could be due to release of intracellular contents or direct modulation of cell signaling, but further investigation is warranted. ${ }^{135}$
FIG. 6. Schematic depicting generalized electrode placement and resulting treatment zone for a pancreatic tumor encasing the superior mesenteric vessels. The proximity of the pancreas to these vessels and other vasculature limits interventional options for a large number of patients. In such cases, IRE has shown promise as it allows for focal ablation of the tumor without longterm injury to these critical proteinaceous structures. Additionally, the zone of reversible electroporation could be used in the future to increase uptake of adjuvant molecules and/or chemotherapeutics in the periphery of the ablation, further increasing efficacy.

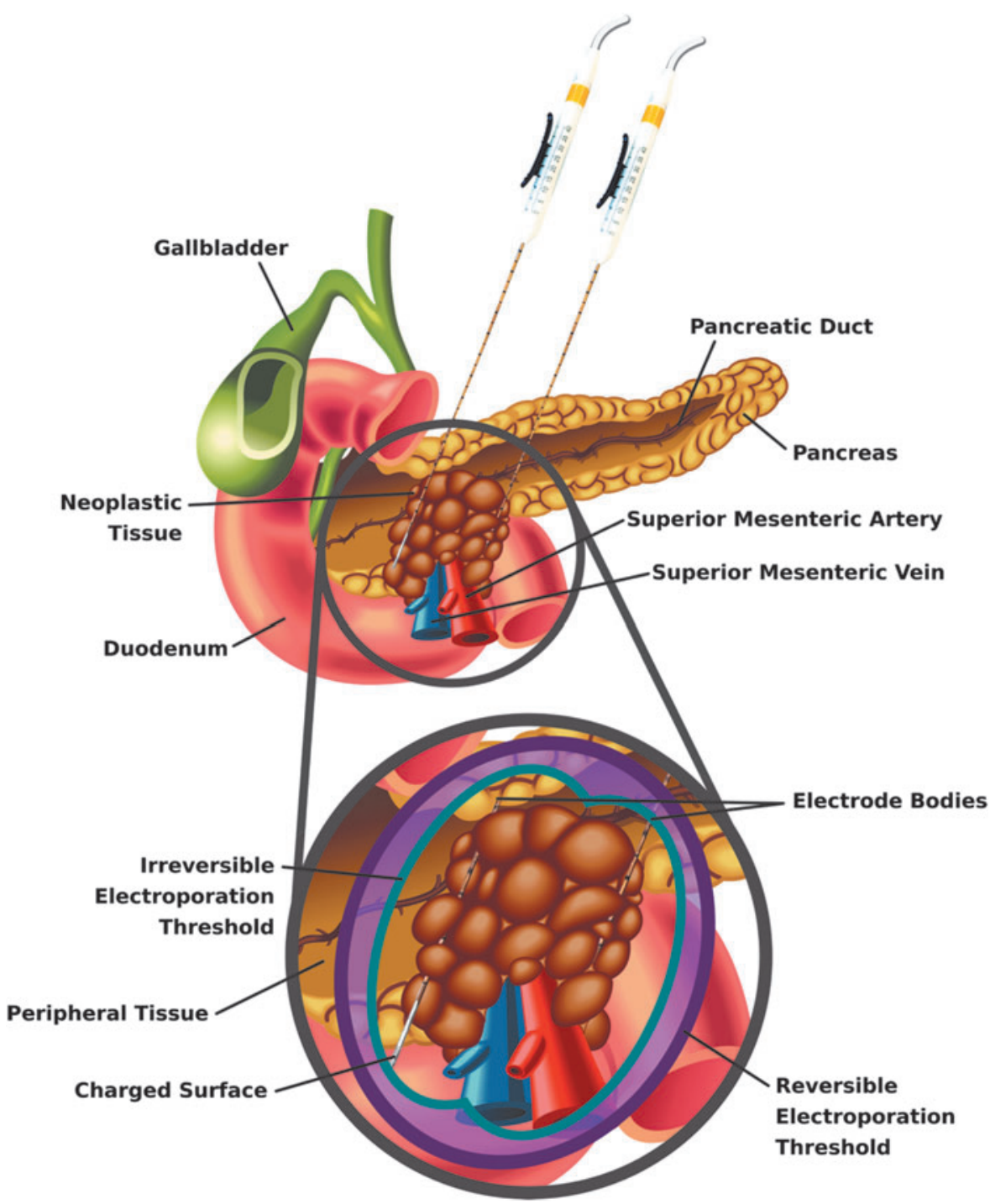


To assess the translational potential of these early findings, Lin et al. used IRE alone or alongside allogenic NK cell therapy in 71 patients with stage III or IV pancreatic cancer. $^{136}$ IRE with NK therapy increased survival of patients with either stage III or IV disease and produced substantial increases in $\mathrm{CD}^{+}$and $\mathrm{CD} 8^{+} \mathrm{T}$ lymphocytes, $\mathrm{NK}$ cells, and $\mathrm{B}$ cells for stage III patients. Interestingly, Th2 cytokine (IL-4, IL-10) levels remained relatively unchanged while Th1 cytokines (IL-2 and IFN- $\gamma$ ) increased in response to both treatments, consistent with preclinical findings. ${ }^{130}$ This initial study, along with a similar investigation for patients with unresectable liver cancer, indicates that IRE could play a "priming" role by preparing the tumor microenvironment for effective exploitation by immunotherapy. ${ }^{137}$

Further clinical examination has shown that immune modulation occurs quickly after IRE and that attenuation of the highly immunosuppressive environment, as seen by a reduction in regulatory $\mathrm{T}$ cells, can be achieved for at least 2 weeks. ${ }^{138,139}$ These results are supported by the finding that IRE and anti-PD1 immunotherapy work synergistically to improve survival in a murine model of pancreatic cancer. ${ }^{140}$ This study again showed the presence of immune memory that was able to address tumor rechallenge. Similar to the findings of He et al., ${ }^{138}$ infiltrating $\mathrm{CD} 8^{+} \mathrm{T}$ lymphocytes were associated with improved survival. These results are paving the way toward the clinical translation of combinatorial treatment strategies that capitalize on the ability of IRE to create an immunostimulatory microenvironment.

\section{High-frequency IRE}

In 2011, Arena et al. numerically showed that short pulses (500 ns $-2 \mu \mathrm{s}$ ) of alternating polarity may be more favorable a

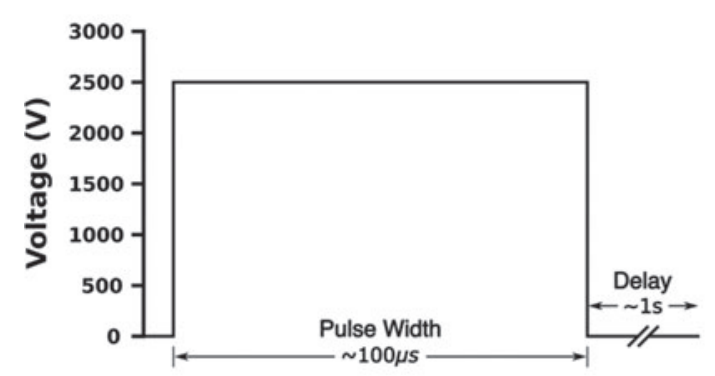

b
H-FIRE

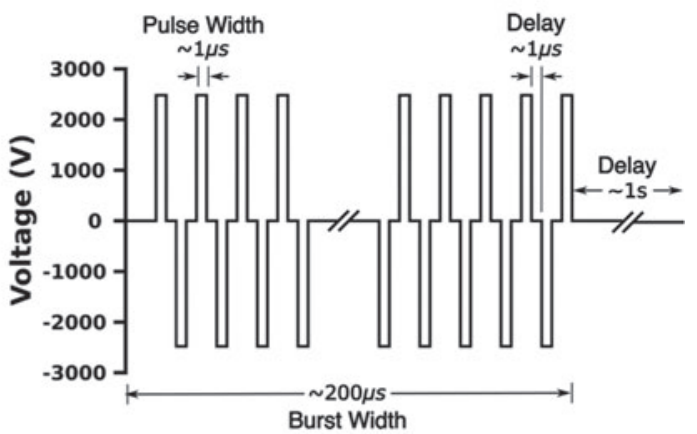

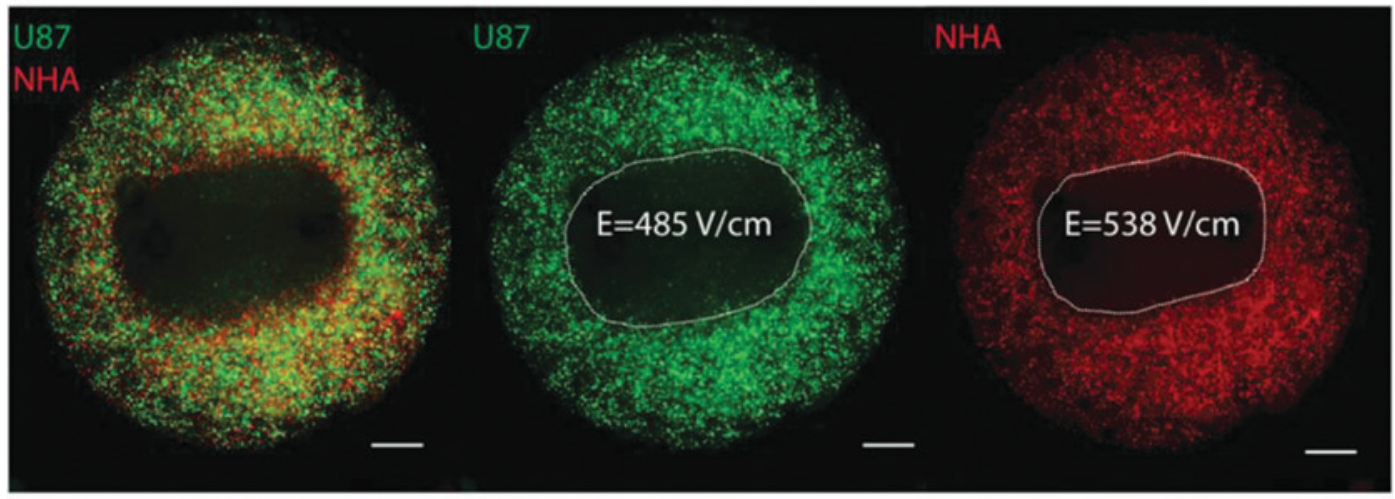

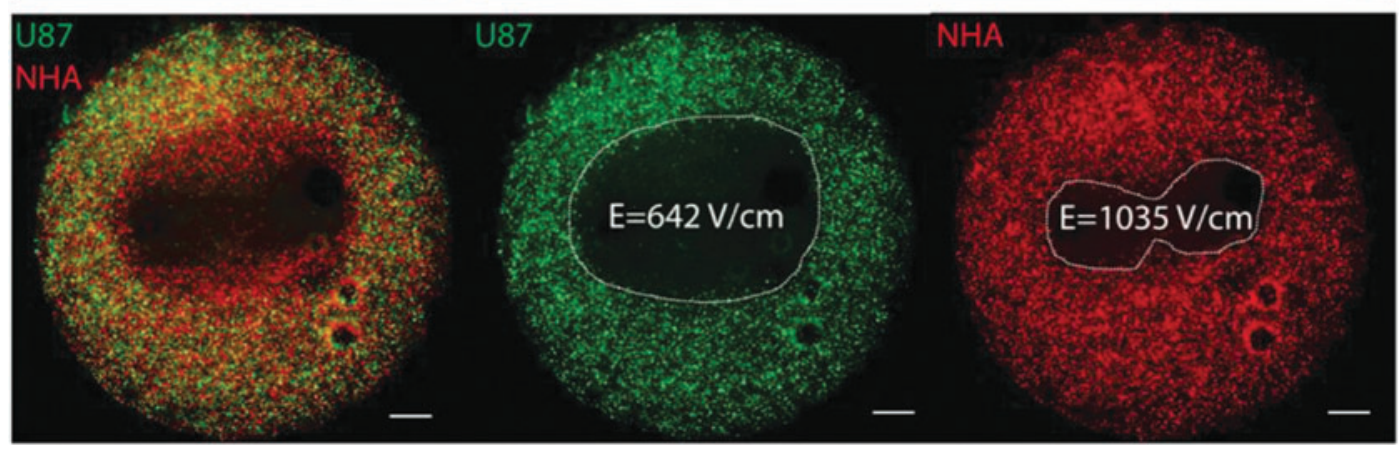

FIG. 7. H-FIRE selectively targets malignant cells. IRE and H-FIRE employ voltage waveforms (a) with different characteristic frequencies, which result in unique biological effects. IRE-treated malignant (U251) and healthy (NHA) astrocytes (b, top) exhibit similar electric field thresholds for cell death. However, lethal electric field thresholds for H-FIRE (b, bottom) are much lower for U251 cells than NHAs, demonstrating the capacity of H-FIRE to target malignant phenotypes. (b) Published in Ivey et al. ${ }^{144}$ reprinted under Creative Commons Attribution 4.0 International License. H-FIRE, high-frequency irreversible electroporation. Scale bar represents $1 \mathrm{~mm}$. 
for predictable tissue ablation in heterogeneous tissues than long monopolar pulses. ${ }^{141}$ In this initial computational analysis, a tissue domain consisting of an external layer of skin surrounding a cylinder of fat was modeled to study the extent of electroporation induced by pulsatile voltage waveforms with different characteristic frequencies between $250 \mathrm{kHz}$ and $2 \mathrm{MHz}$. High-frequency voltage waveforms were shown to more uniformly penetrate the heterogeneous system. A follow-up study introduced the term high-frequency irreversible electroporation (H-FIRE, Fig. 7a) and showed the ability of these waveforms to generate nonthermal ablations in rat brain without muscle contractions. ${ }^{142} \mathrm{H}$-FIRE has since been used to treat intracranial malignancies in canines, and low-amplitude H-FIRE waveforms have been used to transiently disrupt the blood-brain barrier. ${ }^{143}$

In addition to the aforementioned advantages, in vitro work has shown that H-FIRE may exhibit selectivity toward malignant phenotypes (Fig. 7b). ${ }^{144}$ Furthermore, H-FIRE ablation in a 4T1 murine mammary tumor model stimulated a local inflammatory response and resulted in systemic immune activation capable of reducing distant metastases, suggesting that this technology is well suited for both standalone and combinatorial treatment strategies. ${ }^{145}$ In its first clinical evaluation, H-FIRE was used to treat PCa in 40 men without ECG synchronization. ${ }^{146}$ Four weeks after treatment, evaluated patients had complete preservation of urinary (40/40) and sexual (14/14) function. Additionally, no cardiac-related side effects were noted. These emerging data support the notion that H-FIRE will likely augment the clinical efficacy of highvoltage PEFs in the coming years. Future studies investigating oncological outcomes in larger randomized patient cohorts are warranted and will be critical to this development.

\section{Concluding Remarks}

IRE has an array of potential advantages over existing technologies. Although promising results have been demonstrated, dissemination of knowledge and training is critical to the widespread adoption of IRE. Differences in physician experience, patient inclusion criteria, and reporting have led to inconsistencies in the application of IRE. Additionally, studies thus far have primarily evaluated IRE in patients with advanced disease and with numerous comorbidities. Despite this, IRE has shown to be a viable option for certain patients diagnosed with tumors of the prostate, liver, kidney, and pancreas. With proper patient selection and choice of pulse paradigms, IRE can improve outcomes as demonstrated by the in vivo and clinical results provided herein. Future developments involving combinatorial therapeutic regimens and alternate waveforms have shown exciting early results, and further evaluation will likely expand the clinical impact of IRE in the coming years.

\section{Acknowledgments}

The authors would like to thank Natalie Beitel-White, Emma Folsom, and Philip M. Graybill for useful discussions and assistance in reviewing the article. We would also like to acknowledge figure editing assistance from Josie Duncan.

\section{Authors' Contributions}

K.N.A. and R.V.D. conceived and planned the content and organization of the article. K.N.A. and R.V.D. wrote, revised, and edited the article. K.N.A. and R.V.D. conceived and edited figures. Both the authors reviewed and approved submission of the final version of the article. This review has been submitted only to Bioelectricity and is not published, in press, or submitted elsewhere.

\section{Author Disclosure Statement}

R.V.D. is an inventor on pending and issued patents related to irreversible electroporation. The authors declare no other conflicts of interest.

\section{Funding Information}

This article was not directly supported by external funding.

\section{References}

1. Weaver JC, Chizmadzhev YA. Theory of electroporation: A review. Bioelectrochem Bioenerg 1996;41:135-160.

2. Stampfli R, Willi M. Membrane potential of a Ranvier node measured after electrical destruction of its membrane. Experientia 1957;13:297-298.

3. Stampfli R. Reversible electrical breakdown of the excitable membrane of a Ranvier Node. An Acad Bras Cien 1958;30:57-63.

4. Sale A, Hamilton W. Effects of high electric fields on microorganisms: I. Killing of bacteria and yeasts. Biochim Biophys Acta 1967;148:781-788.

5. Neumann E, Rosenheck K. Permeability changes induced by electric impulses in vesicular membranes. J Membr Biol 1972;10:279-290.

6. Kinosita K, Tsong TY. Formation and resealing of pores of controlled sizes in human erythrocyte membrane. Nature 1977;268:438-441.

7. Kinosita K, Tsong TY. Survival of sucrose-loaded erythrocytes in the circulation. Nature 1978;272:258-260.

8. Kinosita K, Tsong TY. Voltage-induced conductance in human erythrocyte membranes. Biochim Biophys Acta 1979;554:479-497.

9. Kinosita K, Tsong TY. Hemolysis of human erythrocytes by a transient electric field. Proc Natl Acad Sci U S A 1977;74:1923-1927.

10. Abidor IG, Arakelyan VB, Chernomordik LV, et al. Electric breakdown of bilayer lipid membranes. I. The main experimental facts and their qualitative discussion. Bioelectrochem Bioenerg 1979;6:37-52.

11. Neumann E, Schaefer-Ridder M, Wang Y, et al. Gene transfer into mouse lyoma cells by electroporation in high electric fields. EMBO J 1982;1:841-845.

12. Okino M, Mohri H. Effects of a high-voltage electrical impulse and an anticancer drug on in vivo growing tumors. Jpn J Cancer Res 1987;78:1319-1321.

13. Mir LM, Orlowski S, Belehradek J, et al. Electrochemotherapy potentiation of antitumour effect of bleomycin by local electric pulses. Eur J Cancer Clin Oncol 1991;27:68-72.

14. Davalos RV, Mir LM, Rubinsky B. Tissue ablation with irreversible electroporation. Ann Biomed Eng 2005;33: 223-231.

15. Maor E, Ivorra A, Leor J, et al. The effect of irreversible electroporation on blood vessels. Technol Cancer Res Treat 2007;6:307-312.

16. Ueshima E, Schattner M, Mendelsohn R, et al. Transmural ablation of the normal porcine common bile duct with 
catheter-directed irreversible electroporation is feasible and does not affect duct patency. Gastrointest Endosc 2018;87:300.e1-e300.e6.

17. Li W, Fan Q, Ji Z, et al. The effects of irreversible electroporation (IRE) on nerves. PLoS One 2011;6: e18831.

18. Edd JF, Horowitz L, Davalos RV, et al. In vivo results of a new focal tissue ablation technique: Irreversible electroporation. IEEE Trans Biomed Eng 2006;53:1409-1415.

19. Lee EW, Loh CT, Kee ST. Imaging guided percutaneous irreversible electroporation: Ultrasound and immunohistological correlation. Technol Cancer Res Treat 2007; 6:287-293.

20. Rubinsky B, Onik G, Mikus P. Irreversible electroporation: A new ablation modality-Clinical implications. Technol Cancer Res Treat 2007;6:37-48.

21. Rubinsky J, Onik G, Mikus P, et al. Optimal parameters for the destruction of prostate cancer using irreversible electroporation. J Urol 2008;180:2668-2674.

22. Onik G, Mikus P, Rubinsky B. Irreversible electroporation: Implications for prostate ablation. Technol Cancer Res Treat 2007;6:295-300.

23. Bower M, Sherwood L, Li Y, et al. Irreversible electroporation of the pancreas: Definitive local therapy without systemic effects. J Surg Oncol 2011;104:22-28.

24. Pech M, Janitzky A, Wendler JJ, et al. Irreversible electroporation of renal cell carcinoma: A first-in-man phase i clinical study. Cardiovasc Intervent Radiol 2011;34: 132-138.

25. Dupuy DE, Aswad B, Ng T. Irreversible electroporation in a swine lung model. Cardiovasc Intervent Radiol 2011;34: 391-395.

26. Deodhar A, Monette S, Single GW, et al. Percutaneous irreversible electroporation lung ablation: Preliminary results in a porcine model. Cardiovasc Intervent Radiol 2011;34:1278-1287.

27. Garcia PA, Rossmeisl JH, Robertson J, et al. Pilot study of irreversible electroporation for intracranial surgery. Conf Proc IEEE Eng Med Biol Soc 2009;2009:6513-6516.

28. Garcia PA, Neal RE, Rossmeisl JH, et al. Non-thermal irreversible electroporation for deep intracranial disorders. Conf Proc IEEE Eng Med Biol Soc 2010;2010:27432746.

29. Ellis TL, Garcia PA, Rossmeisl JH, et al. Nonthermal irreversible electroporation for intracranial surgical applications: Laboratory investigation. J Neurosurg 2011; 114:681-688.

30. Garcia PA, Rossmeisl JH, Neal RE, et al. Intracranial nonthermal irreversible electroporation: In vivo analysis. J Membr Biol 2010;236:127-136.

31. Kotnik T, Kramar P, Pucihar G, et al. Cell membrane electroporation-Part 1: The phenomenon. IEEE Electr Insul Mag 2012;28:14-23.

32. Levine ZA, Vernier PT. Life cycle of an electropore: Field-dependent and field-independent steps in pore creation and annihilation. J Membr Biol 2010;236:27-36.

33. Böckmann RA, De Groot BL, Kakorin S, et al. Kinetics, statistics, and energetics of lipid membrane electroporation studied by molecular dynamics simulations. Biophys J 2008;95:1837-1850.

34. Chen C, Smye SW, Robinson MP, et al. Membrane electroporation theories: A review. Med Biol Eng Comput 2006;44:5-14.
35. Tieleman DP. The molecular basis of electroporation. BMC Biochem 2004;5:1-12.

36. Deamer DW, Bramhall J. Permeability of lipid bilayers to water and ionic solutes. Chem Phys Lipids 1986;40: 167-188.

37. Jansen M, Blume A. A comparative study of diffusive and osmotic water permeation across bilayers composed of phospholipids with different head groups and fatty acyl chains. Biophys J 1995;68:997-1008.

38. Akinlaja J, Sachs F. The breakdown of cell membranes by electrical and mechanical stress. Biophys J 1998;75: 247-254.

39. Tokman M, Lee JHJ, Levine ZA, et al. Electric fielddriven water dipoles: Nanoscale architecture of electroporation. PLoS One 2013;8:e61111.

40. Kramar P, Delemotte L, Lebar AM, et al. Molecular-level characterization of lipid membrane electroporation using linearly rising current. J Membr Biol 2012;245:651-659.

41. Pavlin M, Miklavcic D. Theoretical and experimental analysis of conductivity, ion diffusion and molecular transport during cell electroporation-Relation between short-lived and long-lived pores. Bioelectrochemistry 2008;74:38-46.

42. Schwan HP. Electrical Properties of Tissue and Cell Suspensions. Adv Biol Med Phys 1957;5:147-209.

43. Kotnik T, Pucihar G. Induced transmembrane voltageTheory, modeling, and experiments. In: Miklavčič D, Pakhomov A, Markov M, eds. Advanced Electroporation Techniques in Biology and Medicine. Boca Raton: CRC Press, 2010: 51-70.

44. Pastushenko V, Chizmadzhev Y, Arakelyan VB. 247Electrical breakdown of bilayer lipid membranes II. Calculation of the membrane lifetime in the steady-state diffusion approximation. Bioelectrochemistry 1979;6: 53-62.

45. Neu JC, Krassowska W. Asymptotic model of electroporation. Phys Rev E 1999;59:3471-3482.

46. Debruin KA, Krassowska W. Modeling electroporation in a single cell. I. effects of field strength and rest potential. Biophys J 1999;77:1213-1224.

47. Glaser RW, Leikin SL, Chernomordik LV, et al. Reversible electrical breakdown of lipid bilayers: Formation and evolution of pores. Biochim Biophys Acta 1988;940: 275-287.

48. Debruin KA, Krassowska W. Electroporation and shockinduced transmembrane potential in a cardiac fiber during defibrillation strength shocks. Ann Biomed Eng 1998;26: 584-596.

49. Sersa G, Miklavcic D, Cemazar M, et al. Electrochemotherapy in treatment of tumours. Eur J Surg Oncol 2008;34:232-240.

50. Al-Sakere B, André F, Bernat C, et al. Tumor ablation with irreversible electroporation. PLoS One 2007;2:e1135.

51. Lee RC, Zhang D, Hannig J. Biophysical injury mechanisms in electrical shock trauma. Annu Rev Biomed Eng 2000;2:477-509.

52. Chen W, Zhongsheng Z, Lee RC. Supramembrane potential-induced electroconformational changes in sodium channel proteins: A potential mechanism involved in electric injury. Burns 2006;32:52-59.

53. Frandsen SK, Gissel H, Hojman P, et al. Direct therapeutic applications of calcium electroporation to effectively induce tumor necrosis. Cancer Res 2012;72:1336-1341. 
54. Kanthou C, Kranjc S, Sersa G, et al. The endothelial cytoskeleton as a target of electroporation-based therapies. Mol Cancer Ther 2006;5:3145-3152.

55. Rubinsky L, Guenther E, Mikus P, et al. Electrolytic effects during tissue ablation by electroporation. Technol Cancer Res Treat 2016;15:NP95-NP103.

56. Clausen T, Gissel $\mathrm{H}$. Role of $\mathrm{Na}+, \mathrm{K}+$ pumps in restoring contractility following loss of cell membrane integrity in rat skeletal muscle. Acta Physiol Scand 2005;183: 263-271.

57. Gissel H, Lee RC, Gehl J. Electroporation and cellular physiology. In: Kee ST, Gehl J, Lee EW, eds. Clinical Aspects of Electroporation. New York: Springer, 2011: 9-17.

58. Vogel JA, Van Veldhuisen E, Agnass P, et al. Timedependent impact of irreversible electroporation on pancreas, liver, blood vessels and nerves: A systematic review of experimental studies. PLoS One 2016;11:e0166987.

59. Davalos RV, Rubinsky B. Temperature considerations during irreversible electroporation. Int J Heat Mass Transf 2008;51:5617-5622.

60. O'Brien TJ, Arena CB, Davalos RV. Thermal considerations with tissue electroporation. In: Kulacki FA, ed. Handbook of Thermal Science and Engineering. New York: Springer Inter, 2017: 1-31.

61. O'Brien TJ, Lorenzo MF, Zhao Y, et al. Cycled pulsing to mitigate thermal damage for multi-electrode irreversible electroporation therapy. Int J Hyperth 2019;36: 953-963.

62. Deodhar A, Dickfeld T, Single GW, et al. Irreversible electroporation near the heart: Ventricular arrhythmias can be prevented with ECG synchronization. AJR Am J Roentgenol 2011;196:330-335.

63. Sel D, Cukjati D, Batiuskaite D, et al. Sequential finite element model of tissue electropermeabilization. IEEE Trans Biomed Eng 2005;52:816-827.

64. Neal RE, Garcia PA, Robertson JL, et al. Experimental characterization and numerical modeling of tissue electrical conductivity during pulsed electric fields for irreversible electroporation treatment planning. IEEE Trans Biomed Eng 2012;59:1076-1085.

65. Jiang C, Davalos RV, Bischof JC. A review of basic to clinical studies of irreversible electroporation therapy. IEEE Trans Biomed Eng 2015;62:4-20.

66. Kos B, Voigt P, Miklavcic D, et al. Careful treatment planning enables safe ablation of liver tumors adjacent to major blood vessels by percutaneous irreversible electroporation (IRE). Radiol Oncol 2015;49:234-241.

67. Latouche EL, Sano MB, Lorenzo MF, et al. Irreversible electroporation for the ablation of pancreatic malignancies: A patient-specific methodology. J Surg Oncol 2017; 115:711-717.

68. Siegel RL, Miller KD, Jemal A. Cancer statistics, 2019. CA Cancer J Clin 2019;69:7-34.

69. Heidenreich A, Bolla M, Joniau S, et al. Guidelines on prostate cancer. Eur Urol 2008;53:68-80.

70. Nam RK, Cheung P, Herschorn S, et al. Incidence of complications other than urinary incontinence or erectile dysfunction after radical prostatectomy or radiotherapy for prostate cancer: A population-based cohort study. Lancet Oncol 2014;15:223-231.

71. Li J, Djenaba JA, Soman A, et al. Recent trends in prostate cancer incidence by age, cancer stage, and grade, the United States, 2001-2007. Prostate Cancer 2012;2012:1-8.
72. Onik G, Rubinsky B. Irreversible electroporation: First patient experience focal therapy of prostate cancer. In: Nagel J, ed. Irreversible Electroporation. Berlin: Springer Berlin Heidelberg, 2010: 235-247.

73. Tsivian M, Polascik TJ. Bilateral focal ablation of prostate tissue using low-energy direct current (LEDC): A preclinical canine study. BJU Int 2013;112:526-530.

74. Valerio M, Stricker PD, Ahmed HU, et al. Initial assessment of safety and clinical feasibility of irreversible electroporation in the focal treatment of prostate cancer. Prostate Cancer Prostatic Dis 2014;17:343-347.

75. van den Bos W, de Bruin DM, Veelo D, et al. Quality of life and safety outcomes following irreversible electroporation treatment for prostate cancer: Results from a phase I-II study. J Cancer Sci Ther 2015;7:312-321.

76. van den Bos W, Jurhill RR, de Bruin DM, et al. Histopathological outcomes after irreversible electroporation for prostate cancer: Results of an ablate and resect study. J Urol 2016;196:552-559.

77. van den Bos W, de Bruin DM, Jurhill RR, et al. The correlation between the electrode configuration and histopathology of irreversible electroporation ablations in prostate cancer patients. World J Urol 2016;34:657-664.

78. van den Bos W, Scheltema MJ, Siriwardana AR, et al. Focal irreversible electroporation as primary treatment for localized prostate cancer. BJU Int 2018;121:716-724.

79. Guenther E, Klein N, Zapf S, et al. Prostate cancer treatment with irreversible electroporation (IRE): Safety, efficacy and clinical experience in 471 treatments. PLoS One 2019;14:e0215093.

80. Howlader N, Noone A, Krapcho M, et al. SEER Cancer Statistics Review, 1975-2016. Bethesda: SEER, 2018.

81. Pandya GJ, Shelat VG. Radiofrequency ablation of pancreatic ductal adenocarcinoma: The past, the present and the future. World J Gastrointest Oncol 2015;7:6-11.

82. Charpentier KP, Wolf F, Noble L, et al. Irreversible electroporation of the pancreas in swine: A pilot study. HPB (Oxford) 2010;12:348-351.

83. Martin RCG, McFarland $\mathrm{K}$, Ellis S, et al. Irreversible electroporation therapy in the management of locally advanced pancreatic adenocarcinoma. J Am Coll Surg 2012; 215:361-369.

84. Narayanan G, Hosein PJ, Arora G, et al. Percutaneous irreversible electroporation for downstaging and control of unresectable pancreatic adenocarcinoma. J Vasc Interv Radiol 2012;23:1613-1621.

85. Martin RCG, Kwon D, Chalikonda S, et al. Treatment of 200 locally advanced (Stage III) pancreatic adenocarcinoma patients with irreversible electroporation safety and efficacy. Ann Surg 2015;262:486-492.

86. Leen E, Picard J, Stebbing J, et al. Percutaneous irreversible electroporation with systemic treatment for locally advanced pancreatic adenocarcinoma. J Gastrointest Oncol 2018;9:275-281.

87. Martin RCG, McFarland K, Ellis S, et al. Irreversible electroporation in locally advanced pancreatic cancer: Potential improved overall survival. Ann Surg Oncol 2013;20:443-449.

88. Paiella S, De Pastena M, D’Onofrio M, et al. Palliative therapy in pancreatic cancer-Interventional treatment with radiofrequency ablation/irreversible electroporation. Transl Gastroenterol Hepatol 2018;3:80.

89. Belfiore G, Belfiore MP, Reginelli A, et al. Concurrent chemotherapy alone versus irreversible electroporation 
followed by chemotherapy on survival in patients with locally advanced pancreatic cancer. Med Oncol 2017; 34-38.

90. Månsson C, Brahmstaedt R, Nilsson A, et al. Percutaneous irreversible electroporation for treatment of locally advanced pancreatic cancer following chemotherapy or radiochemotherapy. Eur J Surg Oncol 2016;42:1401-1406.

91. Flak RV, Stender MT, Jensen TM, et al. Treatment of locally advanced pancreatic cancer with irreversible electroporation-A Danish single center study of safety and feasibility. Scand J Gastroenterol 2019;54:252-258.

92. Martin RCG, Scoggins CR, Egnatashvili V, et al. Arterial and venous resection for pancreatic adenocarcinoma: operative and long-term outcomes. Arch Surg 2009;144: 154-159.

93. Akinwande O, Ahmad SS, Van Meter T, et al. CT Findings of patients treated with irreversible electroporation for locally advanced pancreatic cancer. J Oncol 2015; 2015:1-8.

94. Altekruse SF, Henley SJ, Cucinelli JE, et al. Changing hepatocellular carcinoma incidence and liver cancer mortality rates in the United States. Am J Gastroenterol 2014;109:542-553.

95. Iavarone M, Colombo M. Management of hepatocellular carcinoma. Gastroenterol Hepatol (N Y) 2014;10: 544-551.

96. Zhang M, Ma H, Zhang J, et al. Comparison of microwave ablation and hepatic resection for hepatocellular carcinoma: A meta-analysis. Onco Targets Ther 2017;10:4829_ 4839.

97. Niemeyer DJ, Simo KA, Iannitti DA, et al. Ablation therapy for hepatocellular carcinoma: Past, present and future perspectives. Hepatic Oncol 2014;1:67-79.

98. Kim KR, Thomas S. Complications of image-guided thermal ablation of liver and kidney neoplasms. Semin Intervent Radiol 2014;31:138-148.

99. Thomson KR, Cheung W, Ellis SJ, et al. Investigation of the safety of irreversible electroporation in humans. J Vasc Interv Radiol 2011;22:611-621.

100. Kingham TP, Karkar AM, D'Angelica MI, et al. Ablation of perivascular hepatic malignant tumors with irreversible electroporation. J Am Coll Surg 2012;215:379-387.

101. Cannon R, Ellis S, Hayes D, et al. Safety and early efficacy of irreversible electroporation for hepatic tumors in proximity to vital structures. J Surg Oncol 2013;107: 544-549.

102. Narayanan G, Bhatia S, Echenique A, et al. Vessel patency post irreversible electroporation. Cardiovasc Intervent Radiol 2014;37:1523-1529.

103. Silk MT, Wimmer T, Lee KS, et al. Percutaneous ablation of peribiliary tumors with irreversible electroporation. J Vasc Interv Radiol 2014;25:112-118.

104. Dollinger M, Müller-Wille R, Zeman F, et al. Irreversible electroporation of malignant hepatic tumors-Alterations in venous structures at subacute follow-up and evolution at mid-term follow-up. PLoS One 2015;10:e0135773.

105. Alnaggar M, Qaid AM, Chen J, et al. Electroporation of malignant liver tumors: Effect on laboratory values. Oncol Lett 2018;16:3881-3888.

106. Bhutiani N, Philips P, Scoggins CR, et al. Evaluation of tolerability and efficacy of irreversible electroporation (IRE) in treatment of Child-Pugh B (7/8) hepatocellular carcinoma (HCC). HPB (Oxford) 2016;18:593-599.
107. Schicho A, Niessen C, Haimerl M, et al. Long-term survival after percutaneous irreversible electroporation of inoperable colorectal liver metastases. Cancer Manag Res 2019;11:317-322.

108. Mafeld S, Wong JJ, Kibriya N, et al. Percutaneous irreversible electroporation (IRE) of hepatic malignancy: A bi-institutional analysis of safety and outcomes. Cardiovasc Intervent Radiol 2019;42:577-583.

109. Appelbaum L, Ben-David E, Faroja M, et al. Irreversible electroporation ablation: Creation of large-volume ablation zones in in vivo porcine liver with four-electrode arrays. Radiology 2014;270:416-424.

110. Cornelis FH, Cindrič H, Kos B, et al. Peri-tumoral metallic implants reduce the efficacy of irreversible electroporation for the ablation of colorectal liver metastases. Cardiovasc Intervent Radiol 2019. [Epub ahead of print]; DOI: $10.1007 / \mathrm{s} 00270-019-02300-y$.

111. Philips P, Hays D, Martin RCG. Irreversible electroporation ablation (IRE) of unresectable soft tissue tumors: Learning curve evaluation in the first 150 patients treated. PLoS One 2013;8:e76260.

112. Scheffer HJ, Nielsen K, De Jong MC, et al. Irreversible electroporation for nonthermal tumor ablation in the clinical setting: A systematic review of safety and efficacy. J Vasc Interv Radiol 2014;25:997-1011.

113. Verloh N, Jensch I, Lürken L, et al. Similar complication rates for irreversible electroporation and thermal ablation in patients with hepatocellular tumors. Radiol Oncol 2019; 53:116-122.

114. Jones JL, Jones RE, Balasky G. Microlesion formation in myocardial cells by high-intensity electric field stimulation. 1987. www.physiology.org/journal/ajpheart Accessed September 12, 2019.

115. Maor E, Ivorra A, Rubinsky B. Intravascular irreversible electroporation: Theoretical and experimental feasibility study. In: Proceedings of the 30th Annual International Conference of the IEEE Engineering in Medicine and Biology Society, Vancouver, BC, Canada: EMBS'08"Personalized Healthcare through Technology." 2008: 2051-2054.

116. Maor E, Rubinsky B. Endovascular nonthermal irreversible electroporation: A finite element analysis. J Biomech Eng 2010;132:013008.

117. Maor E, Ivorra A, Rubinsky B. Non thermal irreversible electroporation: Novel technology for vascular smooth muscle cells ablation. PLoS One 2009;4:e4757.

118. Phillips M, Maor E, Rubinsky B. Nonthermal irreversible electroporation for tissue decellularization. J Biomech Eng 2010;132:0910031-0910038.

119. Maor E, Ivorra A, Leor J, et al. Irreversible electroporation attenuates neointimal formation after angioplasty. IEEE Trans Biomed Eng 2008;55:2268-2274.

120. Maor E, Ivorra A, Mitchell JJ, et al. Vascular smooth muscle cells ablation with endovascular nonthermal irreversible electroporation. J Vasc Interv Radiol 2010;21: 1708-1715.

121. Sano MB, Neal RE, Garcia PA, et al. Towards the creation of decellularized organ constructs using irreversible electroporation and active mechanical perfusion. Biomed Eng Online 2010;9:83.

122. Lavee J, Onik G, Mikus P, et al. A novel nonthermal energy source for surgical epicardial atrial ablation: Irreversible electroporation. Heart Surg Forum 2007;10:96-101. 
123. Wittkampf FH, Van Driel VJ, Van Wessel H, et al. Feasibility of electroporation for the creation of pulmonary vein ostial lesions. J Cardiovasc Electrophysiol 2011;22: 302-309.

124. Neven K, Van Driel V, Van Wessel H, et al. Myocardial lesion size after epicardial electroporation catheter ablation after subxiphoid puncture. Circ Arrhythmia Electrophysiol 2014;7:728-733.

125. Van Driel VJHM, Neven KGEJ, Van Wessel H, et al. Pulmonary vein stenosis after catheter ablation: Electroporation versus radiofrequency. Circ Arrhythmia Electrophysiol 2014;7:734-738.

126. Witt CM, Sugrue A, Padmanabhan D, et al. Intrapulmonary vein ablation without stenosis: A novel balloon-based direct current electroporation approach. J Am Heart Assoc 2018;7:e009575.

127. Livia C, Sugrue A, Witt T, et al. Elimination of purkinje fibers by electroporation reduces ventricular fibrillation vulnerability. J Am Heart Assoc 2018;7:e009070.

128. Reddy VY, Koruth J, Jais P, et al. Ablation of atrial fibrillation with pulsed electric fields: An ultra-rapid, tissue-selective modality for cardiac ablation. JACC Clin Electrophysiol 2018;4:987-995.

129. Al-Sakere B, Bernat C, André F, et al. A study of the immunological response to tumor ablation with irreversible electroporation. Technol Cancer Res Treat 2007;6: 301-305.

130. Li X, Xu K, Li W, et al. Immunologic response to tumor ablation with irreversible electroporation. PLoS One 2012;7:e48749.

131. Neal RE, Rossmeisl JH, Robertson JL, et al. Improved local and systemic anti-tumor efficacy for irreversible electroporation in immunocompetent versus immunodeficient mice. PLoS One 2013;8:e64559.

132. Shao Q, O'Flanagan S, Lam T, et al. Engineering T cell response to cancer antigens by choice of focal therapeutic conditions. Int J Hyperth 2019;36:130-138.

133. Lee EW, Wong D, Tafti BA, et al. Irreversible electroporation in eradication of rabbit VX2 liver tumor. J Vasc Interv Radiol 2012;23:833-840.

134. Bulvik BE, Rozenblum N, Gourevich S, et al. Irreversible electroporation versus radiofrequency ablation: A comparison of local and systemic effects in a small-animal model. Radiology 2016;280:413-424.

135. Goswami I, Coutermarsh-Ott S, Morrison RG, et al. Irreversible electroporation inhibits pro-cancer inflammatory signaling in triple negative breast cancer cells. Bioelectrochemistry 2017;113:42-50.

136. Lin M, Alnaggar M, Liang S, et al. An important discovery on combination of irreversible electroporation and allogeneic natural killer cell immunotherapy for unresectable pancreatic cancer. Oncotarget 2017;8:101795101807.

137. Yang Y, Qin Z, Du D, et al. Safety and short-term efficacy of irreversible electroporation and allogenic natural killer cell immunotherapy combination in the treatment of patients with unresectable primary liver cancer. Cardiovasc Intervent Radiol 2019;42:48-59.

138. He C, Wang J, Sun S, et al. Immunomodulatory effect after irreversible electroporation in patients with locally advanced pancreatic cancer. J Oncol 2019;2019: $1-13$.

139. Scheffer HJ, Stam AGM, Geboers B, et al. Irreversible electroporation of locally advanced pancreatic cancer transiently alleviates immune suppression and creates a window for antitumor $\mathrm{T}$ cell activation. Oncoimmunology 2019;8:e1652532.

140. Zhao J, Wen X, Tian L, et al. Irreversible electroporation reverses resistance to immune checkpoint blockade in pancreatic cancer. Nat Commun 2019;10:899.

141. Arena CB, Sano MB, Rylander MN, et al. Theoretical considerations of tissue electroporation with highfrequency bipolar pulses. IEEE Trans Biomed Eng 2011; 58:1474-1482.

142. Arena CB, Sano MB, Rossmeisl JH, et al. High-frequency irreversible electroporation (H-FIRE) for non-thermal ablation without muscle contraction. Biomed Eng Online 2011;10:102.

143. Arena CB, Garcia PA, Sano MB, et al. Focal blood-brainbarrier disruption with high-frequency pulsed electric fields. Technology 2014;2:1-8.

144. Ivey JW, Latouche EL, Sano MB, et al. Targeted cellular ablation based on the morphology of malignant cells. Sci Rep 2015;5:1-17.

145. Ringel-Scaia VM, Beitel-White N, Lorenzo MF, et al. High-frequency irreversible electroporation is an effective tumor ablation strategy that induces immunologic cell death and promotes systemic anti-tumor immunity. EBioMedicine 2019;44:112-125.

146. Dong S, Wang H, Zhao Y, et al. First human trial of highfrequency irreversible electroporation therapy for prostate cancer. Technol Cancer Res Treat 2018;17:1-9.

147. Sweeney DC. Quantitative In Vitro Characterization of Membrane Permeability for Electroporated Mammalian Cells. Blacksburg, VA: Virginia Tech, 2018.

148. Kotnik T, Miklavčič D. Theoretical evaluation of voltage inducement on internal membranes of biological cells exposed to electric fields. Biophys J 2006;90:480-491.

149. Gascoyne PRC, Pethig R, Burt JPH, et al. Membrane changes accompanying the induced differentiation of Friend murine erythroleukemia cells studied by dielectrophoresis. Biochem Biophys Acta 1993;1149:119-126.

150. Hu Q, Joshi RP, Beskok A. Model study of electroporation effects on the dielectrophoretic response of spheroidal cells. J Appl Phys 2009;106:024701.

151. Smith KC, Gowrishankar TR, Esser AT, et al. The spatially distributed dynamic transmembrane voltage of cells and organelles due to $10 \mathrm{~ns}$ pulses: Meshed transport networks. IEEE Trans Plasma Sci 2006;34:1394-1404.

152. Ye H, Cotic M, Kang EE, et al. Transmembrane potential induced on the internal organelle by a time-varying magnetic field: A model study. J Neuroeng Rehabil 2010; $7: 1-15$.

153. Vasilkoski Z, Esser AT, Gowrishankar TR, et al. Membrane electroporation: The absolute rate equation and nanosecond time scale pore creation. Phys Rev E Stat Nonlin Soft Matter Phys 2006;74(Pt 1):021904.

154. Srimathveeravalli G, Cornelis F, Mashni J, et al. Comparison of ablation defect on MR imaging with computer simulation estimated treatment zone following irreversible electroporation of patient prostate. Springerplus 2016; 5:1-9.

155. Ting F, Tran M, Böhm M, et al. Focal irreversible electroporation for prostate cancer: Functional outcomes and short-term oncological control. Prostate Cancer Prostatic Dis 2016;19:46-52.

156. Murray KS, Ehdaie B, Musser J, et al. Pilot study to assess safety and clinical outcomes of irreversible electropora- 
tion for partial gland ablation in men with prostate cancer. J Urol 2016;196:883-890.

157. Scheltema MJ, Chang JI, van den Bos W, et al. Impact on genitourinary function and quality of life following focal irreversible electroporation of different prostate segments. Diagnostic Interv Radiol 2018;24:268-275.

158. Mansson C, Bergenfeldt M, Brahmstaedt R, et al. Safety and preliminary efficacy of ultrasound-guided percutaneous irreversible electroporation for treatment of localized pancreatic cancer. Anticancer Res 2014;34:289-293.

159. Paiella S, Butturini G, Frigerio I, et al. Safety and feasibility of irreversible electroporation (IRE) in patients with locally advanced pancreatic cancer: Results of a prospective study. Dig Surg 2015;32:90-97.

160. Kluger MD, Epelboym I, Schrope BA, et al. Singleinstitution experience with irreversible electroporation for T4 pancreatic cancer: First 50 patients. Ann Surg Oncol 2016;23:1736-1743.

161. Lambert L, Horejs J, Krska Z, et al. Treatment of locally advanced pancreatic cancer by percutaneous and intraoperative irreversible electroporation: General hospital cancer center experience. Neoplasma 2016;63:269-273.

162. Yan L, Chen YL, Su M, et al. A single-institution experience with open irreversible electroporation for locally advanced pancreatic carcinoma. Chin Med J (Engl) 2016; 129:2920-2925.

163. Narayanan G, Hosein PJ, Beulaygue IC, et al. Percutaneous image-guided irreversible electroporation for the treatment of unresectable, locally advanced pancreatic adenocarcinoma. J Vasc Interv Radiol 2017;28:342-348.

164. Scheffer HJ, Vroomen LGPH, De Jong MC, et al. Ablation of locally advanced pancreatic cancer with percutaneous irreversible electroporation: Results of the phase I/ II PANFIRE study. Radiology 2017;282:585-597.

165. Vogel JA, Rombouts SJ, de Rooij T, et al. Induction chemotherapy followed by resection or irreversible electroporation in locally advanced pancreatic cancer (IMPALA): A prospective cohort study. Ann Surg Oncol 2017;24:2734-2743.

166. Zhang Y, Shi J, Zeng J, et al. Percutaneous irreversible electroporation for ablation of locally advanced pancreatic cancer experience from a Chinese institution. Pancreas 2017;46:e12-e14.

167. Sugimoto K, Moriyasu F, Tsuchiya T, et al. Irreversible electroporation for nonthermal tumor ablation in patients with locally advanced pancreatic cancer: Initial clinical experience in Japan. Intern Med 2018;57:3225-3231.

168. Liu S, Qin Z, Xu J, et al. Irreversible electroporation combined with chemotherapy for unresectable pancreatic carcinoma: A prospective cohort study. Onco Targets Ther 2019;12:1341-1350.

169. Månsson C, Brahmstaedt R, Nygren P, et al. Percutaneous irreversible electroporation as first-line treatment of locally advanced pancreatic cancer. Anticancer Res 2019; 39:2509-2512.

170. Cheung W, Kavnoudias H, Roberts S, et al. Irreversible electroporation for unresectable hepatocellular carcinoma: Initial experience and review of safety and outcomes. Technol Cancer Res Treat 2013;12:233-241.

171. Scheffer HJ, Nielsen K, van Tilborg AAJM, et al. Ablation of colorectal liver metastases by irreversible elec- troporation: Results of the COLDFIRE-I ablate-and-resect study. Eur Radiol 2014;24:2467-2475.

172. Eisele R, Chopra S, Glanemann M, et al. Risk of local failure after ultrasound guided irreversible electroporation of malignant liver tumors. Interv Med Appl Sci 2014;6: 147-153.

173. Hosein PJ, Echenique A, Loaiza-Bonilla A, et al. Percutaneous irreversible electroporation for the treatment of colorectal cancer liver metastases with a proposal for a new response evaluation system. J Vasc Interv Radiol 2014;25:1233-1239.e2.

174. Dollinger M, Beyer LP, Haimerl M, et al. Adverse effects of irreversible electroporation of malignant liver tumors under CT fluoroscopic guidance: A single-center experience. Diagnostic Interv Radiol 2015;21:471-475.

175. Niessen C, Igl J, Pregler B, et al. Factors associated with short-term local recurrence of liver cancer after percutaneous ablation using irreversible electroporation: A prospective single-center study. J Vasc Interv Radiol 2015; 26:694-702.

176. Eller A, Schmid A, Schmidt J, et al. Local control of perivascular malignant liver lesions using percutaneous irreversible electroporation: Initial experiences. Cardiovasc Intervent Radiol 2015;38:152-159.

177. Niessen C, Beyer LP, Pregler B, et al. Percutaneous ablation of hepatic tumors using irreversible electroporation: A prospective safety and midterm efficacy study in 34 patients. J Vasc Interv Radiol 2016;27:480-486.

178. Granata V, de Lutio di Castelguidone E, Fusco R, et al. Irreversible electroporation of hepatocellular carcinoma: Preliminary report on the diagnostic accuracy of magnetic resonance, computer tomography, and contrast-enhanced ultrasound in evaluation of the ablated area. Radiol Med 2016;121:122-131.

179. Frühling P, Nilsson A, Duraj F, et al. Single-center nonrandomized clinical trial to assess the safety and efficacy of irreversible electroporation (IRE) ablation of liver tumors in humans: Short to mid-term results. Eur J Surg Oncol 2017;43:751-757.

180. Langan RC, Goldman DA, D’Angelica MI, et al. Recurrence patterns following irreversible electroporation for hepatic malignancies. J Surg Oncol 2017;115:704-710.

181. Niessen C, Thumann S, Beyer L, et al. Percutaneous irreversible electroporation: long-term survival analysis of 71 patients with inoperable malignant hepatic tumors. Sci Rep 2017;7:43687.

182. Barabasch A, Distelmaier M, Heil P, et al. Magnetic resonance imaging findings after percutaneous irreversible electroporation of liver metastases: A systematic longitudinal study. Invest Radiol 2017;52:23-29.

Address correspondence to: Rafael V. Davalos, PhD

Department of Biomedical Engineering and Mechanics Virginia Tech-Wake Forest University 325 Stanger Street Blacksburg, VA 24061

Email: davalos@vt.edu 